\title{
Overcoming CDK4/6 inhibitor resistance in ER-positive breast cancer
}

\author{
Neil Portman 1,2, Sarah Alexandrou1,2, Emma Carson 1,2, Shudong Wang ${ }^{3}$, Elgene Lim ${ }^{1,2}$ and C Elizabeth Caldon 1,2
}

${ }^{1}$ The Kinghorn Cancer Centre, Garvan Institute of Medical Research, Sydney, New South Wales, Australia

2St. Vincent's Clinical School, Faculty of Medicine, UNSW Sydney, New South Wales, Australia

${ }^{3}$ Centre for Drug Discovery and Development, Cancer Research Institute, University of South Australia, Adelaide, South Australia, Australia

Correspondence should be addressed to C E Caldon: I.caldon@garvan.org.au

\begin{abstract}
Three inhibitors of CDK4/6 kinases were recently FDA approved for use in combination with endocrine therapy, and they significantly increase the progression-free survival of patients with advanced estrogen receptor-positive (ER+) breast cancer in the first-line treatment setting. As the new standard of care in some countries, there is the clinical emergence of patients with breast cancer that is both CDK4/6 inhibitor and endocrine therapy resistant. The strategies to combat these cancers with resistance to multiple treatments are not yet defined and represent the next major clinical challenge in ER+ breast cancer. In this review, we discuss how the molecular landscape of endocrine therapy resistance may affect the response to CDK4/6 inhibitors, and how this intersects with biomarkers of intrinsic insensitivity. We identify the handful of pre-clinical models of acquired resistance to CDK4/6 inhibitors and discuss whether the molecular changes in these models are likely to be relevant or modified in the context of endocrine therapy resistance. Finally, we consider the crucial question of how some of these changes are potentially amenable to therapy.
\end{abstract}

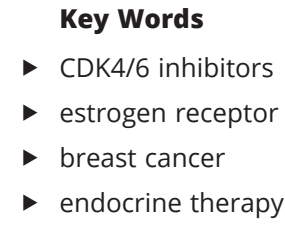

Endocrine-Related Cancer (2019) 26, R15-R30

\section{Overview of the cell cycle}

Dysregulation of the complex regulatory network that controls cell cycle progression is a hallmark of cancer (Hanahan \& Weinberg 2011). A major axis of dysregulation is the gateway to cell cycle entry, which is controlled by the retinoblastoma $(\mathrm{Rb})$ protein. $\mathrm{Rb}$ restricts progression from $G_{1}$ phase into $S$ phase by binding and suppressing E2F transcription factors. This is overcome by cyclin-dependent kinase 4/6 (CDK4/6) phosphorylation of the $\mathrm{Rb}$ protein, which leads to E2F release, and a transcriptional program for proliferation is activated, committing the cell to $G_{1}$ exit. Subsequently, there is a cascade of downstream signalling events that ultimately promotes the activity of cyclin E/CDK2 complexes, the phosphorylation of further target proteins and progression into S phase and DNA replication (Kato et al. 1993, Burkhart \& Sage 2008).

Regulation of CDK4/6 activity is key to the deactivation of the Rb protein. CDK4 and CDK6 become active when CDK4/6 form heterodimers with D-type cyclins, which are upregulated and post-translationally modified in response to mitogenic signalling by the RAS/ MAPK and PI3K/AKT/mTOR signal transduction cascades. Entry into the cell cycle is suppressed by two families of CDK inhibitors, INK4 (p16 INK4A, p15 INK4B, p18 INK4C and p19INK4D) and CIP/KIP (p21 Waf1/Cip1, p27Kip1, p57Kip2) (Sherr 1996). INK4 proteins selectively inhibit the cyclin D-CDK4/6 complex (Sherr \& Roberts 1999, Sheppard \& McArthur 2013) to induce cell cycle arrest and senescence 
(Kim \& Sharpless 2006). CIP/KIP proteins inhibit both CDK4/6 and CDK2 complexes but have the additional effect of stabilising these complexes and preventing cyclin degradation (Prall et al. 1997). In the presence of stable

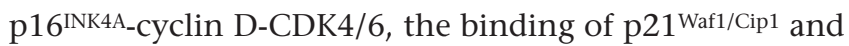
p27 Kip1 to CDK2 complexes will reinforce cell cycle arrest (Sherr \& Roberts 1999).

Dysregulation of the cyclin-CDK-Rb axis by upregulation of cyclin-CDK activity and/or abrogation of suppressors are features of many tumour types. It is therefore unsurprising that this axis is recognised as a key target for therapeutic intervention (Musgrove et al. 2011). Research has focussed on small-molecule inhibition of CDK function and such CDK inhibitors have been designed, developed and trialled in the clinic with increasing success over the last few years.

\section{The development of CDK inhibitors}

CDK4 and CDK6 are part of the CDK family of serine/ threonine kinases (Peyressatre et al. 2015). The initial discovery of cyclin-dependent kinases was in the context of the cell cycle where 'cyclins' were cyclically degraded and includes CDK1, CDK2, CDK4 and CDK6. Since then, further CDK functions have been identified for the transcriptional machinery (CDK7, CDK8, CDK9, CDK12), DNA damage response (CDK12) and in tissue specific functions (CDK5) (Reviewed by Malumbres 2014, Lenjisa et al. 2017, Philip et al. 2018). Despite these diverse functions, the CDKs are structurally very similar, due to the fact that context-specific cyclins are activated to control each function.

CDK inhibitors are a class of pharmacological agents used to target dysregulated CDK activity in malignant cells. The mechanisms of several first-generation CDK inhibitors have been studied in a variety of cancer types, but few have successfully transitioned to a clinical setting (Asghar et al. 2015). A major barrier to the clinical development of first-generation inhibitors was lack of selectivity due to structural similarity between the CDKs (Shapiro 2006, Michaud et al. 2010). Compounds such as flavopiridol (CDK1, CDK2, CDK4, CDK6, CDK7 and CDK9, trialled in patients with a range of haematological malignancies and solid tumours) and roscovitine (CDK2, CDK7 and CDK9, trialled in patients with non-small-cell lung cancer (NSCLC) (NCT00372073), triple-negative breast cancer (NCT01333423) and other advanced solid tumours (NCT00999401)) failed clinical trials, demonstrating limited efficacy and considerable toxicity (Lapenna \& Giordano 2009). Second-generation pan-CDK inhibitors had greater selectivity across a smaller number of CDKs, and a reduced toxicity profile, but they showed a lesser degree of CDK4/6 inhibitory activity. For example, the pan-CDK inhibitors dinaciclib and SNS-032 target CDK1, CDK2, CDK5, CDK9 and CDK12, and CDK2, CDK7 and CDK9 respectively (Asghar et al. 2015). Dinaciclib is currently being trialled on patients with multiple myeloma, NSCLC, melanoma, advanced hematologic, breast and pancreatic malignancies and other solid tumours and has reached phase II clinical trials for some applications. More recently, dinaciclib was shown to be a potent inhibitor of CDK12 with implications for its use in homologous repair-deficient tumour types in combination with PARP inhibitors (Johnson et al. 2016), a finding that is now being investigated in patients (NCT01434316).

The relative failure of these first- and secondgeneration inhibitors led to the search for inhibitors highly selective to individual CDKs and their associated cellular functions. Pharmacological (Tadesse et al. 2018, Yin et al. 2018) and computer-aided (Kalra et al. 2017) approaches are now being employed to design the next generation of CDK inhibitors with higher potency and, crucially, higher specificity - a key attribute for the successful deployment of CDK inhibitors. There has been some progress made in targeting non-cell cycle CDKs such as CDK9 and CDK12 (Johnson et al. 2016, Li et al. 2017), but the inhibitors that have progressed furthest and have now entered clinical use are those targeted at CDK4/6.

\section{CDK4/6 inhibitors}

All CDK4/6 inhibitor compounds are designed by targeting the ATP-binding domains of the proteins (Asghar et al. 2015). The pharmaceutical lead compounds that have been translated into clinical use are palbociclib (Ibrance; Pfizer) (Fry et al. 2004), ribociclib (Kisqali; Novartis) (Infante et al. 2014) and abemaciclib (Verzenio; Eli Lilly) (Patnaik et al. 2016). These compounds are highly selective for CDK4/6 over other members of CDK family compared to their historical counterparts. Both palbociclib and ribociclib have $>100$-fold higher affinity for CDK4 and CDK6 relative to other cell cycle CDKs and CDK9 (Tadesse et al. 2017). In contrast, abemaciclib is less selective, with only six-fold higher affinity for CDK4/6 than it has for CDK9 and has some activity towards CDK1, CDK2 and CDK5 at higher doses (Gelbert et al. 2014, Tripathy et al. 2017) (Table 1). Despite being less selective, in a direct comparison, abemaciclib was found to more efficiently pass through the blood-brain barrier than palbociclib (Raub et al. 2015), which widens 
Table 1 CDK4/6 inhibitor specificities.

\begin{tabular}{|c|c|c|c|}
\hline & $\begin{array}{l}\text { Palbociclib } \\
\text { (Fry et al. 2004) }\end{array}$ & $\begin{array}{c}\text { Ribociclib } \\
\text { (Tripathy et al. } \\
\text { 2017) }\end{array}$ & $\begin{array}{c}\text { Abemaciclib } \\
\text { (Gelbert et al. } \\
\text { 2014) }\end{array}$ \\
\hline \multicolumn{4}{|l|}{$\mathrm{IC}_{50}(\mathrm{nmol} / \mathrm{L})$} \\
\hline $\begin{array}{l}\text { CDK4-cyclin } \\
\text { D1/D3 }\end{array}$ & $9-11$ & 10 & 2 \\
\hline $\begin{array}{l}\text { CDK6-cyclin } \\
\text { D1/D2/D3 }\end{array}$ & 15 & 39 & 10 \\
\hline $\begin{array}{l}\text { CDK1-cyclin } \\
\text { B }\end{array}$ & $>10,000$ & $>100,000$ & $>1000$ \\
\hline $\begin{array}{l}\text { CDK2-cyclin } \\
\text { A/E }\end{array}$ & $>10,000$ & $>50,000$ & $>500$ \\
\hline CDK5-p25 & $>10,000$ & $>40,000$ & $>300$ \\
\hline CDK9-cyclin T & $\begin{array}{l}\text { Not } \\
\text { determined }\end{array}$ & $\begin{array}{l}\text { Not } \\
\text { determined }\end{array}$ & 57 \\
\hline
\end{tabular}

$I_{50}$, half maximal inhibitory concentration; in vitro kinase assay.

its potential application to brain cancers and secondary brain metastases (NCT02308020).

Recent studies using chemoproteomics (Sumi et al. 2015), thermal proteome profiling (Miettinen et al. 2018) and a mass spectrometry-based competition assay have shown that palbociclib, ribociclib and abemaciclib can inhibit a spectrum of other kinases and that the inhibition profiles of palbociclib and abemaciclib were not similar with the exception of CDK4/6 (Cousins et al. 2018). Notably, it was found that in cell line models abemaciclib, but not palbociclib or ribociclib, activated wnt signalling via inhibition of glycogen synthase kinase (GSK) 3B and subsequent stabilisation of $\beta$-catenin. GSK3 $\beta$ activity also plays an important role in the regulation of cyclin D

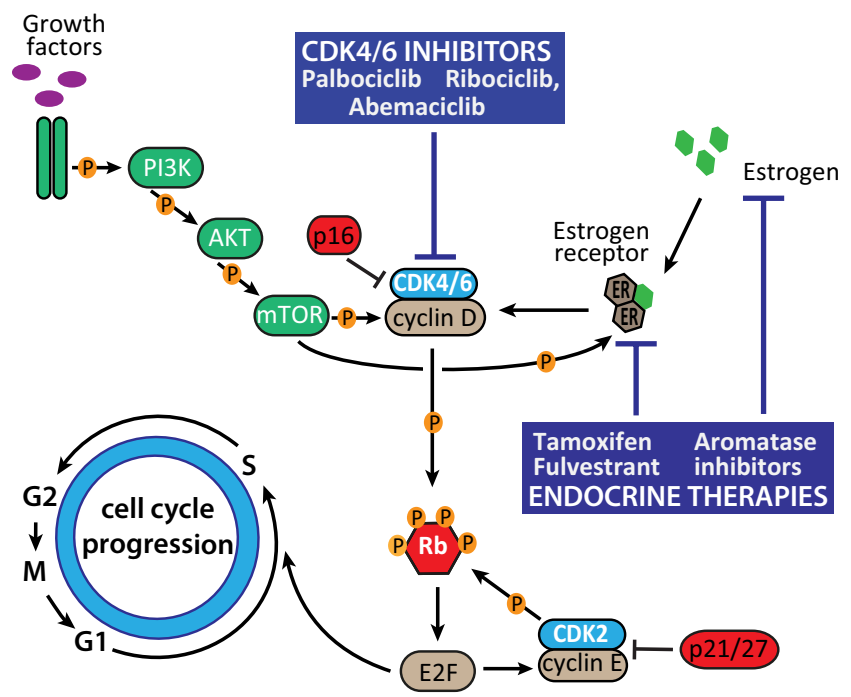

Figure 1

Regulation of cell cycle in ER+ breast cancer. The key pathways in promoting entry into the cell cycle in ER+ breast cancer and the nodes to which current therapies are targeted. family proteins at both the transcriptional and proteomic level such that inhibition of GSK3B is expected to increase the levels of cyclin D (Takahashi-Yanaga \& Sasaguri 2008).

The clinical relevance of the off-target kinase inhibitory activity for each of these drugs has yet to be fully assessed (Chen et al. 2016). The increased potency of abemaciclib toward CDK9 (reported in some, but not all studies) (Gong et al. 2017) correlates with a gastrointestinal toxicity profile specifically in those patients (Shohdy et al. 2017). Conversely, abemaciclib allows for continuous dosing, whereas palbociclib and ribociclib require a break in treatment of 1 week in four in order to allow for neutrophil recovery. All three inhibitors are associated with toxicities resulting in loss of haematocytes (Kassem et al. 2018), consistent with a role for CDK6 in the activation of haematopoetic stem cells (Scheicher et al. 2015). Toxicities associated with all three drugs are, however, considered to be manageable and reversible (Spring et al. 2017).

This family of compounds have found a natural home in the treatment of advanced ER+ breast cancer (Lapenna \& Giordano 2009, Musgrove et al. 2011). ER+ breast cancer is by far the most common subtype of breast cancer, representing approximately $70 \%$ of breast cancers in women. Estrogen is mitogenic and drives cell proliferation, partly through the increase in levels of cyclin D1 and CDK4/6 activity (Filmus et al. 1994).

\section{Clinical development of CDK4/6 inhibitors in endocrine-resistant breast cancer}

Endocrine therapy is the bedrock of systemic therapy for ER+ breast cancer. Adjuvant therapy comprises 5-10 years or more of ER-directed endocrine therapy such as tamoxifen and aromatase inhibitors to inhibit ER-driven activation of cell cycle progression. Approximately $50 \%$ of patients with early stage ER+ breast cancer obtain benefit from adjuvant endocrine therapy, resulting in a reduction in breast cancer mortality by approximately $40 \%$ (Early Breast Cancer Trialists' Collaborative Group 2015). However, resistance to endocrine therapy leading to early stage ER+ breast cancer recurrence is not uncommon and inevitable in the setting of advanced disease. Importantly, the majority of these cancers have a perturbed but essentially intact $\mathrm{Rb}$ axis downstream of the mechanism of endocrine resistance, making them highly suitable for CDK4/6 inhibitor treatment (Ertel et al. 2010) (Fig. 1).

Early preclinical breast cancer studies demonstrated that palbociclib preferentially inhibited the proliferation of ER+ in contrast to ER- breast cancer models in vitro 
(Finn et al. 2009). Phase III clinical trials have shown that the combination therapy of CDK4/6 inhibitors and endocrine therapy for advanced ER+ breast cancer, improves progression free survival (PFS) when compared to endocrine therapy alone; overall survival data are yet to be published. Therefore, the combination of CDK4/6 inhibitor and endocrine therapy is now standard of care as first-line therapy for advanced ER+ breast carcinoma in many countries.

Phase III trials of all three CDK4/6 inhibitors in the first-line setting in combination with non-steroidal aromatase inhibitors and in the second-line setting in combination with fulvestrant has been completed. Palbociclib was the first CDK4/6 inhibitor approved by the FDA in February 2015. It was granted accelerated approval in combination with letrozole for the first-line treatment of advanced ER+ HER2- breast cancer due to the phase II PALOMA-1 trial (Finn et al. 2015). The follow-up phase III PALOMA-2 trial demonstrated that palbociclib and letrozole improved PFS from 14.5 to 24.8 months, when compared to letrozole alone (hazard ratio $0.58 ; 95 \%$ CI $0.46-0.72, P<0.001$ ) (Finn et al. 2016). It also received FDA approval in February 2016 for a second indication, the treatment of advanced ER+ HER2- breast cancer in combination with fulvestrant after progression following endocrine therapy from the phase III PALOMA-3 trial (Cristofanilli et al. 2016) (Table 2).

Also approved for clinical use are ribociclib and abemaciclib. The phase III MONALEESA-2 trial with ribociclib and letrozole as first-line treatment for advanced ER+ HER2- breast cancer showed improved PFS, leading to FDA approval in March 2017 (Hortobagyi et al. 2016, 2018). More recently, the phase III MONALEESA-3 trial with ribociclib and fulvestrant as first- and secondline treatment for advanced ER+ HER2- breast cancer demonstrated an improved PFS (Slamon et al. 2018). Abemaciclib was FDA approved in September 2017 in combination with fulvestrant as a second-line treatment after the phase II MONARCH-2 trial (Sledge et al. 2017) and as monotherapy after progression on endocrine therapy and chemotherapy from the phase II MONARCH-1 trial (Dickler et al. 2017). It was later approved in February 2018 in combination with letrozole as first-line treatment based on results from the phase III MONARCH-3 trial (Goetz et al. 2017).

CDK4/6 inhibitors are given as oral tablets and are generally well tolerated. Common toxicities include nausea, diarrhoea, fatigue, neutropenia (however, febrile neutropenia is uncommon), leukopenia, anaemia and thrombocytopenia (Shah et al. 2018). Patients require regular full blood counts, liver function tests and ECGs.

Current clinical questions include which CDK4/6 inhibitor to choose, how to best sequence therapy and whether to add to the same endocrine therapy regime. The recent TREND study (Malorni et al. 2018) shows that adding palbociclib to the previously administered endocrine therapy led to a PFS advantage in patients who received prior endocrine therapy for $>6$ months (HR 0.53; 95\% CI 0.3-0.9, exploratory $P$-value $=0.02$ ), but not in those who had received less than 6 months of endocrine therapy.

Resistance to CDK4/6 inhibitors is now the major emerging consideration in pre-clinical and clinical drug development. Clinical areas of interest to address resistance include identifying predictive biomarkers for CDK4/6 inhibitors and novel treatment combinations.

\section{Does endocrine therapy resistance affect CDK4/6 inhibitor sensitivity?}

Endocrine resistance occurs when tumours bypass the cell cycle inhibition of endocrine therapy and return to a proliferative phenotype. Many mechanisms of acquired endocrine resistance have been described, including the upregulation of ER coactivators (e.g. FOXA1), cyclins (particularly D and E class), CDK proteins (CDK2 and CDK6) and mitogen signalling pathways (PI3K and RAS pathways) and/or downregulation of CDK inhibitor proteins (p16 1NK4A, p21 Waf1/Cip1, p27Kip1) (Musgrove \& Sutherland 2009). Genomic and epigenetic mechanisms of endocrine resistance have also been identified, including activating ESR1 mutations, which can occur in up to $40 \%$ of patients with metastatic disease (Jeselsohn et al. 2014, Schiavon et al. 2015) and hypermethylation of estrogen-responsive enhancers, which is associated with reduced ER binding and decreased gene expression of key regulators of ER activity (Stone et al. 2015). Importantly, in most cases functional $\mathrm{Rb}$ protein is retained during the development of endocrine resistance (Musgrove et al. 2011), rendering these tumours amenable to CDK4/6 inhibition (Fig. 1).

CDK4/6 inhibition acts directly downstream of endocrine therapy, and it is therefore inevitable that some mechanisms of resistance will be common to both types of treatments. Endocrine resistance associated with dysregulation of the $\mathrm{Rb}$ axis could, in theory, reduce sensitivity to CDK4/6 inhibition as many of these mechanisms could also impinge on the effectiveness of CDK4/6 inhibitors. Despite this, the success of CDK4/6
C) 2019 Society for Endocrinology Published by Bioscientifica Ltd. Printed in Great Britain 


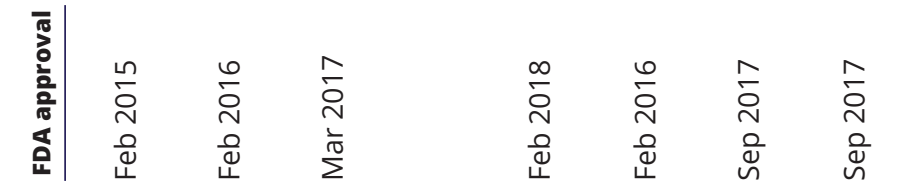

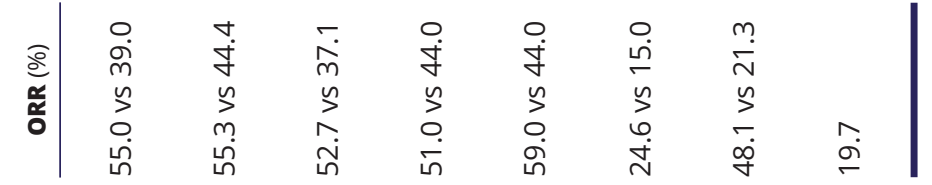

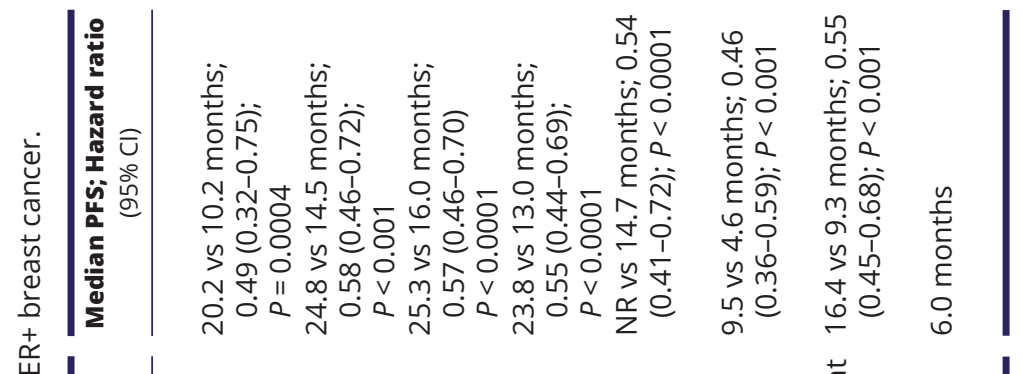

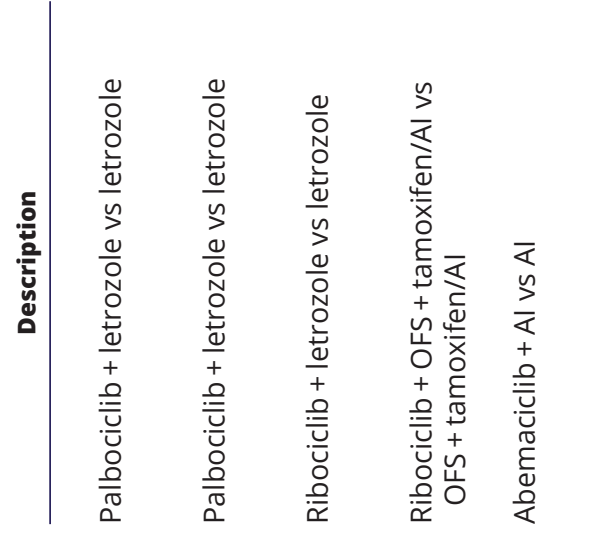

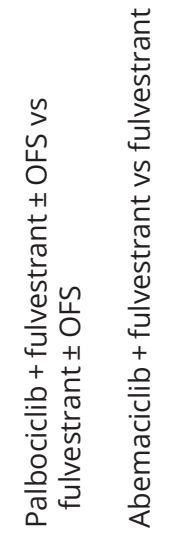

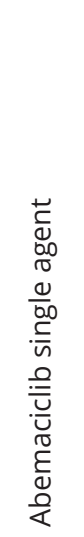

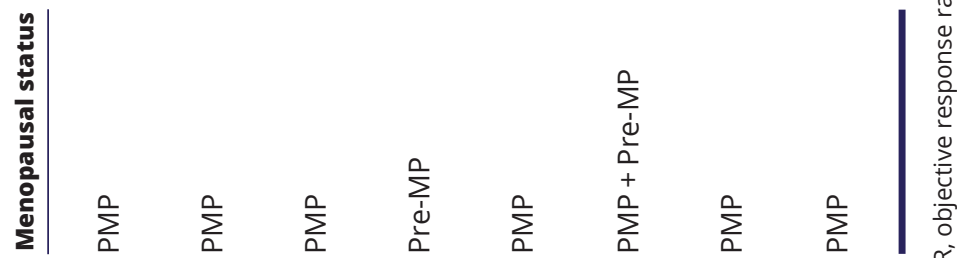

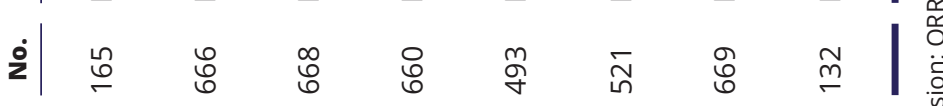
峁

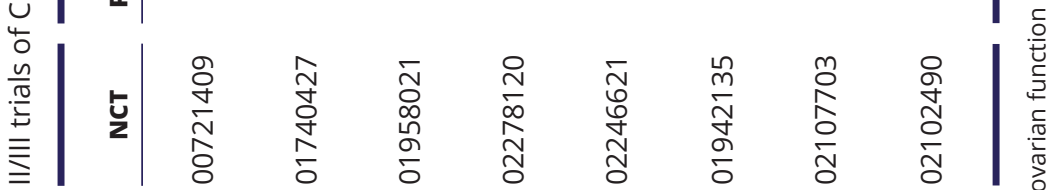

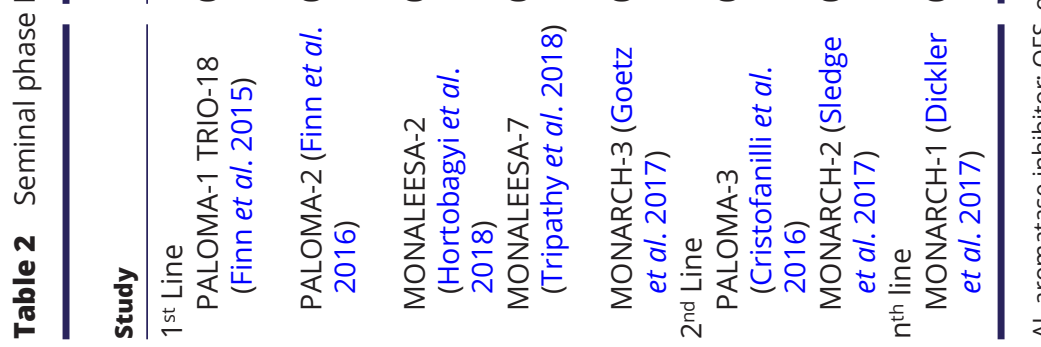


inhibitors clinically (Table 2) suggests that in general, endocrine-resistant tumours maintain sensitivity to CDK4/6 inhibition, particularly when used in combination with endocrine therapy. This has been retrospectively demonstrated for endocrine-resistant tumours with activating ESR1 mutations. In the PALOMA-3 trial, fulvestrant plus palbociclib improved PFS in patients with ESR1 mutant and ESR1 WT circulating tumour DNA (ctDNA), indicating that CDK4/6 inhibitors are effective irrespective of ESR1 mutation status (Fribbens et al. 2016).

In fact, certain manifestations of endocrine therapy resistance may sensitise breast cancer to CDK4/6 inhibitors. Deficiency of mismatch repair caused by MutL mutation in ER+ breast cancer abrogates CHK2-mediated inhibition of CDK4, leading to endocrine resistance. Consequently, CDK4/6 inhibitors are highly effective in MutL-defective ER+ breast cancer cells, and MutL could prove useful as a biomarker to identify patients suitable for CDK4/6 inhibitors (Haricharan et al. 2017). In a window of opportunity trial in patients with early stage breast cancer, palbociclib has been shown to downregulate an E2F signature associated with letrozole resistance, suggesting that this signature could be used to identify high-risk patients who should receive adjuvant CDK4/6 inhibitors in combination with endocrine therapy (Guerrero-Zotano et al. 2018). Finally, a non-canonical function of palbociclib is proteosomal inhibition via the ECM29 protein. High ECM29 is predictive of poorer relapse-free survival in patients receiving endocrine therapy, and thus, CDK4/6 inhibitor therapy may also prove particularly effective for these patients (Miettinen et al. 2018).

\section{Biomarkers of response to CDK4/6 inhibitors for $\mathrm{ER}+$ breast cancer}

Patients with advanced ER+ breast cancer are pre-selected for CDK4/6 inhibitor therapy on the basis that these cancers generally have an intact $\mathrm{Rb}$ axis, and indeed the incidence of $\mathrm{Rb}$ gene deletion/mutation is very rare (3.9\%) in ER+ breast cancer (Ciriello et al. 2015). Studies in preclinical models demonstrate a requirement of intact $\mathrm{Rb}$ for effective CDK4/6 inhibition, supporting its utility as a biomarker (Konecny et al. 2011, Thangavel et al. 2011). This finding has also been validated clinically (Karakas et al. 2016, Hunt et al. 2017). In an examination of the effects of palbociclib on unselected ex vivo tumour explant breast cancer models (Dean et al. 2012), the 2 of 13 models that were insensitive to palbociclib lacked $\mathrm{Rb}$ expression. Studies in glioblastoma cell lines (Michaud et al. 2010) and pancreatic cancer patient-derived xenograft (PDX) models have reached similar conclusions (Chou et al. 2017), with even the low expression of $\mathrm{Rb}$ sufficient to confer insensitivity to CDK4/6 inhibitors (Chou et al. 2017). The use of $\mathrm{Rb}$ as a biomarker of CDK4/6 inhibitor response in $\mathrm{ER}+$ breast cancer could be further refined in combination with low molecular weight cyclin E1 (LMWE). LMWE is a promiscuous cytoplasmic cyclin E1 fragment (Karakas et al. 2016, Hunt et al. 2017) that when complexed with CDK2 can phosphorylate $\mathrm{Rb}$ in the presence of CDK4/6 inhibition (Doostan et al. 2017). Patients with Rb-/ LMWE+ cancers had the shortest PFS in a cohort of 109 patients treated with palbociclib and endocrine therapy (Vijayaraghavan et al. 2017).

Complicating the use of $\mathrm{Rb}$ as a biomarker is the fact that studies of other cancer types suggest that functional $\mathrm{Rb}$ is not an absolute requirement for CDK4/6 inhibitors to demonstrate an effect. In bladder cancer models, palbociclib was found to be as effective in Rb-mutant models as it was in Rb wild-type models, and transcriptome analysis identified FOXM1 as the likely target in the context of Rb mutation (Castellano et al. 2016). Conversely, the presence of $\mathrm{Rb}$ does not guarantee a response to CDK4/6 inhibition, as demonstrated by the poor outcomes of a recent phase II study of $\mathrm{Rb}+$ patients with advanced oesophageal or gastric cancer (Karasic et al. 2018).

Whether or not $\mathrm{Rb}$ is absolutely required for CDK4/6 inhibitor functionality, it is regarded as the canonical target, and other indicators of intrinsic sensitivity are based on their relationship with Rb. The loss of p16 $6^{\mathrm{INK} 4 \mathrm{~A}}$ is postulated to be a marker of sensitivity as this protein inhibits cyclin D1 (Witkiewicz et al. 2011). This is supported by two reported cases with homozygous deletion of the p16 $6^{\mathrm{INK} 4 \mathrm{~A}}$ gene CDKN2A, a collecting duct carcinoma and a uterine leiomyosarcoma, where both were exceptional responders to palbociclib treatment (Elvin et al. 2017, Pal et al. 2017). This observation has not been borne out in other studies. Low p16 $16^{\text {INK4A }}$ did not predict response in a phase II study of palbociclib monotherapy in $\mathrm{Rb}+$ breast tumours (DeMichele et al. 2015) or in the PALOMA-1 study of palbociclib with letrozole for ER+ breast cancer. In PALOMA-1, the treatment of patients with tumours harbouring CDKN2A loss had similar PFS compared to unselected patients when assessing combination palbociclib and letrozole treatment versus letrozole monotherapy (Finn et al. 2015). A potential explanation of the difference between the exceptional responders and the patients of the PALOMA- 1 trial may be that the PALOMA-1 patients were selected for loss of heterozygosity rather than homozygous deletion. 
Conversely, elevated $\mathrm{p} 16^{\mathrm{INK} 4 \mathrm{~A}}$ could be associated with reduced CDK4/6 inhibitor sensitivity as p16 ${ }^{\mathrm{INK} 4 \mathrm{~A}}$ is often elevated in the absence of functional $\mathrm{Rb}$ (Witkiewicz et al. 2011). For example, Rb-/p16 ${ }^{\text {INK4A }}$ elevated tumours had reduced sensitivity in the study of explant breast cancers (Dean et al. 2012). The NeoPalAna trial (neoadjuvant anastrozole with or without palbociclib) identified another INK4 protein, p19 INK4D, which was elevated in gene-expression analysis across patients with tumours intrinsically resistant to palbociclib (Hunt et al. 2017). One possible explanation may be that p19INK4D is transcribed downstream of E2F activity due to non-functional $\mathrm{Rb}$, and further E2F targets, cyclin D3 and CDKN2D were also identified in the patients with refractory tumours. The same group subsequently identified that another E2F target, thymidine kinase 1 , may be useful as a pharmacodynamic biomarker to monitor the initial patient response to CDK4/6 inhibitors (Bagegni et al. 2017).

The PALOMA-1 study assessed CCND1 amplification as a biomarker for use of CDK4/6 inhibitors, but patients receiving palbociclib plus letrozole showed the same improvement regardless of CCND1 amplification status (Finn et al. 2015). However, a systematic screen of 560 cancer cells identified cell lines that were highly sensitive to abemaciclib had high cyclin D-CDK4/6 function or 'D-cyclin-activating features' (Gong et al. 2017). Notably absent from these was CCND1 amplification, but instead it included CCND2/CCND3 amplification, CCND1 translocation or 3'UTR loss, and loss of FBX031, which drives the turnover of cyclin D1. While this study confirmed the important role of cyclin D1 in CDK4/6 inhibitor function, it did not identify a suitable single biomarker for CDK4/6 inhibitor sensitivity, including cyclin D1 itself.

With the dearth of suitable single biomarkers for CDK4/6 inhibitor sensitivity, researchers are now assembling signatures of sensitivity. The 'D-cyclinactivating features' signature described above is one such example, and a similar approach is the RBsig signature, a gene expression signature of $\mathrm{Rb}$ loss of function derived from E2F1 and E2F2 expression in breast cancers that can predict cell lines with sensitivity to palbociclib (Malorni et al. 2016). An alternative approach is a gene signature for inactive CDK4, which predicted insensitivity to palbociclib across different cell lines (Raspe et al. 2017). This 11 gene expression signature is currently being validated in the NeoRHEA phase II trial (NCT03065621), in biopsies before treatment and following four cycles of neo-adjuvant, pre-operative treatment with palbociclib and endocrine therapy.

\section{The emerging tide of CDK4/6 inhibitor resistance in ER+ breast cancer}

The clinical trials on CDK4/6 inhibitors, while highly successful at increasing PFS, have universally yet to demonstrate significant improvement in overall survival. This has slowed the uptake of CDK4/6 inhibitors worldwide, as health economic analyses conclude that the current high costs lead to poor cost-effectiveness ratios for CDK4/6 inhibitor use (Mamiya et al. 2017). Despite this, governments are still being lobbied to support their cost, as their advantages of being orally available with a relatively low toxicity profile means that they provide a tangible improvement in quality of life for patients with advanced ER+ breast cancer. The development of resistance to CDK4/6 inhibitors is inevitable (Xu et al. 2017, Condorelli et al. 2018). In the reported trials that have led to FDA and EMA approval, at least $1 / 3$ of patients recurred on CDK4/6 inhibitors within 2 years, and in the PALOMA- 2 trial $>70 \%$ of patients treated with the palbociclib plus letrozole had progressive disease by 40 months (Finn et al. 2016).

Current knowledge of the molecular mechanisms of CDK4/6 inhibitor resistance is far from complete and is largely based in single agent studies using cell line models. However, several studies have pointed to the acquisition of resistance being a multi-step process: first cells can undergo adaptive changes that may affect durability of response, and this is later followed by long-term acquisition of hard-wired resistance mechanisms (HerreraAbreu et al. 2016, Martin et al. 2017). An important factor in considering these pre-clinical findings is that CDK4/6 inhibition in ER+ breast cancer will predominantly occur in the context of endocrine therapy treatment and/or resistance (Fig. 2).

\section{Short-term adaptation to CDK4/6 inhibitors}

CDK4/6 inhibition results in an immediate and profound $\mathrm{G}_{0} / \mathrm{G}_{1}$ cell cycle arrest in $\mathrm{Rb}+$ cells (Fry et al. 2004), but in some cancer models, this wanes within several days. This 'adaptive response' is postulated to play a role in the acquisition of resistance or at least in the durability of therapeutic response. In ER+ breast cancer cell lines acutely exposed to palbociclib, cell cycle inhibition was temporary; $\mathrm{Rb}$ phosphorylation and markers of $\mathrm{S}$ phase entry returned within $72 \mathrm{~h}$ of first exposure, including increased expression of cyclin D1 (Herrera-Abreu et al. 2016). Non-canonical complexes of cyclin D1 and CDK2 were observed and proposed to be the cause of continued $\mathrm{Rb}$ phosphorylation. Increased CDK2 activity was also 


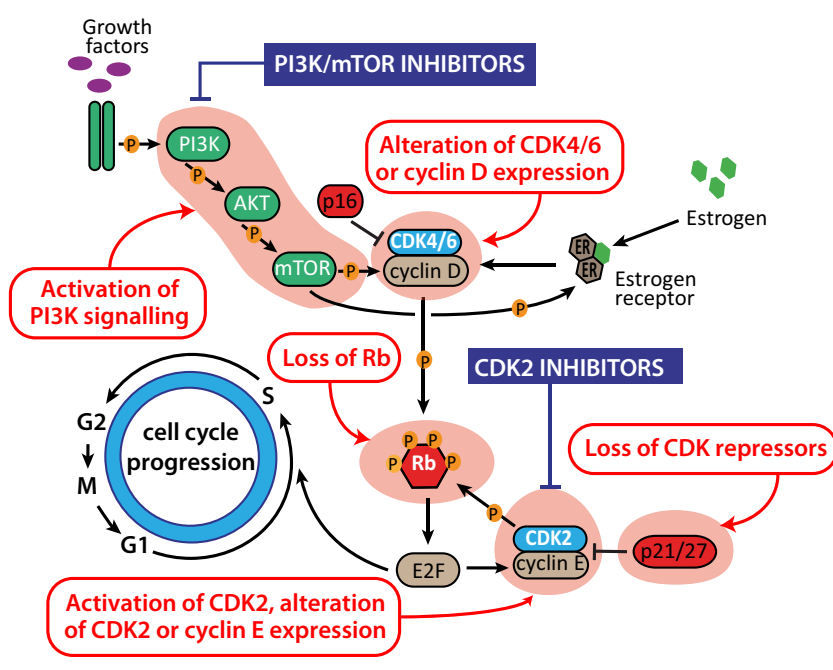

Figure 2

Mechanisms of CDK4/6 inhibitor resistance. The key mechanisms that have so far been implicated in the development of resistance to CDK4/6 inhibitors are highlighted. Possible targets for intervention with currently available drugs or drugs in development are shown.

observed in acute myeloid leukaemia cells after $96 \mathrm{~h}$ of palbociclib treatment, and in this model, the increase in CDK2 activity correlated with a decrease in the p27Kip1 inhibitor protein (Wang et al. 2007).

Interestingly, combination therapies have been shown to inhibit this adaptive response. In breast cancer cells, the addition of a PI3K inhibitor to palbociclib delayed the resumption of $S$ phase entry and abrogated the accumulation of cyclin D1, consistent with the role of the PI3K pathway in promoting cyclin D1 expression (Herrera-Abreu et al. 2016). In an independent study, mTOR pathway inhibition synergised with CDK4/6 inhibition to prevent resumption of proliferation of breast cancer cells, and the combination therapy induced a significant downregulation of E2F target genes (Michaloglou et al. 2018). Finally, endocrine therapy co-treatment with CDK4/6 inhibitors is able to suppress the activation of cell metabolism and cell growth in breast cancer cells (Knudsen \& Witkiewicz 2016).

CDK4/6 inhibition mediates cell senescence, as defined by a prolonged proliferation arrest in combination with molecular markers such as $\beta$-galactosidase (Bollard et al. 2017). A major CDK4/6 target is FOXM1 (Anders et al. 2011), and when CDK4/6 is inhibited, the hypophosphorylated forms of FOXM1 promote a program of senescence (Sharpless \& Sherr 2015). Consequently, the durability of response to CDK4/6 inhibition may affect whether or not cells become senescent with treatment. The program of senescence induced by CDK4/ 6 inhibitors can be augmented through co-treatment to inhibit other pathways. For example, reduced mTOR signalling can augment entry into senescence induced by CDK4/6 inhibition (Yoshida et al. 2016) and autophagy inhibitors in combination with CDK4/6 inhibitors can augment senescence (Karakas et al. 2016, Hunt et al. 2017, Valenzuela et al. 2017).

Effective induction of senescence by CDK4/6 inhibitors could potentially avert long-term resistance, but equally, it appears that the induction of a $G_{1}$ arrest without senescence allows for better synergy with other classes of therapies. For example, palbociclib treatment of melanoma cells for more than 3 days led to the induction of senescence in association with a decreased sensitivity to vemurafenib (Yoshida et al. 2016). Likewise, Rb-expressing sarcoma cell lines with reversible palbociclib-induced cell cycle arrest were sensitive to co-treatment with the WEE1 kinase inhibitor AZD1775 (Francis et al. 2017). Unfortunately, CDK4/6 inhibitor-induced senescence may also result in an undesirable outcome in the stroma through the promotion of a proinflammatory, senescence-associated secretory phenotype (SASP). This SASP phenotype could augment insensitivity to CDK4/6 inhibitors: when palbociclib-induced senescent fibroblasts were co-injected with melanoma cells into an immune-proficient, syngeneic mouse model, it resulted in accelerated tumour growth (Guan et al. 2017).

\section{Long-term acquisition of CDK4/6 inhibitor resistance}

Prolonged exposure to CDK4/6 inhibitors eventually gives rise to resistant cell populations that undergo hardwired changes that are distinct to 'the adaptive response'. A handful of mechanisms have been described in this context, including the loss or mutation of $\mathrm{Rb}$, changes to CDK4/6 and CDK2 signalling and activation of growth signalling pathways. So far, no reports of mutations in either $C D K 4$ or $C D K 6$ that reduce the affinity of CDK4/6 inhibitors have emerged. However, this remains a plausible route for the development of resistance and with the advent of CDK4/6i now being standard of care in the first-line setting, it is likely that previously undescribed mechanisms of CDK4/6i resistance will begin to emerge in the clinic.

\section{Loss or mutation of $\mathbf{R b}$}

By far the most frequently observed change in cells resistant to CDK4/6 inhibitors is loss or mutation of the $\mathrm{Rb}$ protein. This is observed in multiple cell line models from different tumour types (Taylor-Harding et al. 2015, Herrera-Abreu et al. 2016, Bollard et al. 2017). 
Of particular interest is a PDX model exposed to chronic ribociclib treatment that developed partial treatment resistance concurrent with the clonal expansion of a preexisting Rb-null population (Herrera-Abreu et al. 2016). Interestingly, the parental PDX model was derived from a patient who had been previously treated with endocrine therapy and harboured an activating ESR1 mutation (Y537S), a mutation in TP53 and loss of genes encoding p16 INK4A, p15 INK4B and p14ARF. Despite these changes, presumably acquired in response to endocrine therapy, the model responded initially to palbociclib treatment. Following on from these pre-clinical results, the first examples of putative attenuation of Rb function through the emergence of potentially deleterious $\mathrm{Rb}$ mutations in ctDNA, acquired during the development of resistance to CDK4/6 inhibitors in patients, have begun to emerge (Xu et al. 2017, Condorelli et al. 2018).

\section{Activation of CDK4/6 signalling}

Another mechanism of resistance to CDK4/6 inhibition is the upregulation of CDK4 or CDK6 and their cognate cyclins. While CDK6 amplification has been reported (Yang et al. 2017), CDK4 amplification has not been detected in resistance models. Both high and low expression of CDK4 has been noted in resistance models (Bollard et al. 2017, Martin et al. 2017). This may be because while some expression of CDK4 or CDK6 is required for sensitivity to CDK4/6 inhibition, high level amplification of CDK4 on the other hand, as seen in rhabdomyosarcoma, can lead to reduced sensitivity to palbociclib (Olanich et al. 2015). Cyclins D1 and D2 are also upregulated in models of CDK4/6 inhibitor resistance (Taylor-Harding et al. 2015, Jansen et al. 2017, Martin et al. 2017) and high cyclin D3 was observed in patients with ER+ tumours that did not respond to palbociclib (Hunt et al. 2017). Resistance could occur by either non-canonical activation of CDK2 (Herrera-Abreu et al. 2016) or through formation of cyclin D3-CDK4/6 complexes, which appear to phosphorylate $\mathrm{Rb}$ even in the presence of synthetic CDK4/6 inhibitors (Paternot et al. 2014).

\section{Activation of CDK2 signalling}

In normally cycling cells, cyclin E-CDK2 (cyclin E1-CDK2 or cyclin E2-CDK2) complexes phosphorylate $\mathrm{Rb}$ subsequent to phosphorylation by cyclin D-CDK4/6, as part of a second wave of signalling. CDK4/6 inhibition has multiple inhibitory effects on CDK2 action. Without the priming of $\mathrm{Rb}$ by cyclin D1-CDK4/6 phosphorylation, endogenous levels of cyclin E-CDK2 complexes cannot efficiently phosphorylate $\mathrm{Rb}$ to release E2F transcription factors. Cyclin E2 is a transcriptional target of E2F, and hence cyclin E2-CDK2 complexes are also reduced after CDK4/6 inhibition (Caldon et al. 2009). Finally, cyclin E1-CDK2 complexes probably have suppressed activity from the redistribution of $\mathrm{p} 21^{\text {Waf1/Cip1 }}$ and $\mathrm{p} 27^{\mathrm{Kip} 1}$ inhibitors after depletion of cyclin E2-CDK2 complexes (Caldon et al. 2009). In this context, the upregulation of cyclins E1 or E2, or downregulation of their inhibitors can subvert CDK4/6 inhibition.

Cyclin E1, cyclin E2 and CDK2 are upregulated in CDK4/6 inhibitor resistance models (Taylor-Harding et al. 2015, Herrera-Abreu et al. 2016, Bollard et al. 2017, Martin et al. 2017, Yang et al. 2017). Mechanistically this can occur through CCNE1 gene (which encodes cyclin E1) amplification in a single agent CDK4/6 resistant model (Herrera-Abreu et al. 2016), and CCNE2 gene (which encodes cyclin E2) amplification in a combination endocrine therapy/palbociclib resistance model (Martin et al. 2017). Ablation of either cyclin E1 or CDK2 resensitised resistant cells to palbociclib-induced cell cycle arrest (Herrera-Abreu et al. 2016). There are currently no specific CDK2 inhibitors available for clinical use, but newer CDK2 inhibitors currently in development could potentially have a role in CDK4/6 inhibitor-resistant tumours (Caldon et al. 2012).

\section{Growth factor signalling pathways}

$\mathrm{Rb}, \mathrm{CDK} 4 / 6$ and CDK2 are all conduits for growth regulatory signalling pathways to upregulate cell growth and cell cycle progression, and it is not surprising that several signalling pathways can be deregulated to overcome CDK4/6 inhibitors. A kinome-wide siRNA screen identified the PI3K pathway kinase, PDK1, was highly expressed in ribociclib-resistant cells, and sensitised cells to ribociclib (Jansen et al. 2017). While no changes in mTOR signalling components have been documented in long-term resistance models, CDK4/6 inhibitor-resistant cell lines have demonstrated sensitivity to mTORC1/2 inhibition (Michaloglou et al. 2018). Other signalling changes include NRAS amplification or mutation in an NRAS model of melanoma co-treated with MEK1 inhibition and CDK4/6 inhibition (Teh et al. 2018), and alterations in FGF/FGFR signalling in resistance to CDK4/6 inhibitors both alone and in combination with endocrine therapy (Cruz et al. 2018, Formisano et al. 2018, Mao et al. 2018, Shee et al. 2018). Finally, an activating mutation in PIK $3 C A^{\mathrm{E} 545 \mathrm{~K}}$, was shown to display a resistance phenotype to combination 
Table 3 Clinical trials with CDK4/6 inhibitors in combination with inhibitors of PI3 kinase pathway and endocrine therapy in advanced HR+HER2- breast cancer.

\begin{tabular}{|c|c|c|c|}
\hline NCT number & Phase & $\begin{array}{l}\text { Estimated/actual } \\
\text { participants }\end{array}$ & PI3K pathway target \\
\hline 03006172 & I & 156 & PI3 Kinase \\
\hline 02154776 & I & 13 & PI3 Kinase \\
\hline 01872260 & $\mathrm{Ib}$ & 253 & PI3 Kinase \\
\hline 02684032 & I & 120 & PI3 Kinase/mTOR \\
\hline $01655225^{*}$ & I & 130 & PI3 Kinase/mTOR/DNA-PK \\
\hline $02057133^{*}$ & $\mathrm{lb}$ & 198 & PI3 Kinase mTOR/DNA-PK \\
\hline 01857193 & $\mathrm{lb}$ & 132 & mTOR \\
\hline 03128619 & I, II & 102 & PI3 Kinase \\
\hline 02088684 & $\mid \mathrm{b}, \mathrm{I}$ & 70 & PI3 Kinase \\
\hline 02732119 & I, II & 51 & mTOR \\
\hline 02599714 & I, II & 54 & $\mathrm{mTORC} 1 / 2$ \\
\hline 02871791 & $\mathrm{Ib}, \mathrm{II}$ & 32 & mTOR \\
\hline
\end{tabular}

\begin{tabular}{l} 
PI3K pathway \\
inhibitor \\
\hline GDC-0077 \\
Buparlisib \\
Alpelisib \\
Gedatolisib \\
LY3023414 \\
LY3023414 \\
Everolimus \\
Everolimus \\
Copanlisib \\
Alpelisib and \\
buparlisib \\
Everolimus \\
Vistusertib \\
Everolimus
\end{tabular}

\begin{tabular}{l} 
Stage \\
\hline Advanced \\
Advanced \\
Advanced \\
Metastatic \\
Advanced \\
Metastatic \\
Advanced \\
Stage I-IV \\
Advanced \\
Advanced \\
Metastatic \\
Metastatic
\end{tabular}

Endocrine therapy/CDK4/6 inhibitor backbone

Al, fulvestrant/palbociclib Al/ribociclib Al/ribociclib

Al, fulvestrant/palbociclib Al, fulvestrant/abemaciclib Al, fulvestrant/abemaciclib

*HR+/HER2 - breast cancer arms as part of a larger study. $\mathrm{Al}$, aromatase inhibitor.

MEK and CDK4/6 inhibitors, and the outgrowth of a clone expressing this mutation caused recurrence in a melanoma patient treated with these inhibitors (Romano et al. 2018).

\section{Strategies to avert and overcome CDK4/6 inhibitor resistance}

The most frequently detected mechanism of resistance, loss or mutation of $\mathrm{Rb}$, is unfortunately not amenable to targeted therapy. In this situation chemotherapy may be a renewed option, as $\mathrm{Rb}$ disruption sensitises tumours to chemotherapy (Zagorski et al. 2007, Witkiewicz et al. 2012), although the efficacy of this is very dependent upon the combination of tumour type and drug mode of action. Also, CDK4/6 inhibitors can be antagonistic when combined with chemotherapy, especially those with an anti-mitotic effect (Franco et al. 2014, Yoshida et al. 2016), and therefore a cautious approach should be taken with such combinations. As more patients present clinically, these therapies can be systematically assessed to determine if they prolong survival effectively.

The clinical efficacy of endocrine therapy doublet combination therapy with mTOR, PI3K, and CDK4/6 inhibitors (Baselga et al. 2012, Finn et al. 2015, Cristofanilli et al. 2016, Finn et al. 2016, Baselga et al. 2017, Goetz et al. 2017, Sledge et al. 2017, Slamon et al. 2018), and the cross talk between these pathways (Fig. 2), have led to the logical development of clinical trials of triplet therapy combinations of CDK4/6 and PI3K pathway inhibitors with an endocrine therapy backbone (Table 3). Further supporting this strategy is data that has demonstrated that CDK4/6 inhibitors can sensitize PIK3CA mutant tumours to PI3K inhibitors (Vora et al. 2014), and the converse, that CDK4/6 resistant cells have been shown to be sensitive to mTORC1/2 inhibition (Michaloglou et al. 2018). Finally, combined targeting of CDK4/6 and PI3K pathways resulted in greater tumour regression compared with PI3K or CDK4/6 inhibition alone; and triplet therapy with CDK4/6 and PI3K inhibitors was more effective than dual therapy with respect to tumour regression (O'Brien et al. 2014, Herrera-Abreu et al. 2016). In two recent studies, cohorts of heavily pre-treated patients who had received everolimus obtained limited benefit from the addition of palbociclib, suggesting that CDK4/6 inhibitors should be used prior to or concurrently with drugs targeting the PI3K pathway (Dhakal et al. 2018, du Rusquec et al. 2018). The multiple types of PI3K inhibitors in clinical development, combined with the three lead CDK4/6 inhibitors, multiple classes of ER-directed therapies, and next generation selective ER degraders, in different lines of therapy, have resulted in a large number of combinations and permutations, creating a challenge when determining the optimal therapeutic strategy for a given patient. Further complicating matters are the potential for overlapping toxicity and financial implications.

Finally, CDK4/6 inhibitors have also been shown to enhance both tumour antigen presentation, $\mathrm{T}$ cell activation and the efficacy of anti-PD-1 immunotherapy, (c) 2019 Society for Endocrinology Published by Bioscientifica Ltd. Printed in Great Britain 
Table 4 Ongoing clinical trials of CDK4/6 inhibitors in early stage breast cancer.

\begin{tabular}{|c|c|c|c|c|c|c|}
\hline Study & NCT no. & $\begin{array}{l}\text { Estimated } \\
\text { enrolment }\end{array}$ & $\begin{array}{l}\text { Breast cancer } \\
\text { subtype }\end{array}$ & Treatment stage & Treatment & $\begin{array}{l}\text { Primary } \\
\text { outcome } \\
\text { measured }\end{array}$ \\
\hline \multicolumn{7}{|l|}{ Phase III } \\
\hline SAFIA & 03447132 & 400 & $\mathrm{HR}+\mathrm{HER} 2-$ & Neo-adjuvant & $\begin{array}{l}\text { Palbociclib + fulvestrant vs } \\
\text { placebo + fulvestrant }\end{array}$ & pCR rate \\
\hline PALLAS & 02513394 & 5600 & $\mathrm{HR}+\mathrm{HER} 2-$ & $\begin{array}{l}\text { Following neo- } \\
\text { adjuvant } \\
\text { chemotherapy }\end{array}$ & Palbociclib + ET vs ET & IDFS \\
\hline PENELOPE-B & 01864746 & $1250 *$ & $\mathrm{HR}+$ & $\begin{array}{l}\text { Following neo- } \\
\text { adjuvant } \\
\text { chemotherapy }\end{array}$ & Palbociclib + ET vs placebo & IDFS \\
\hline EarLEE-1 & 03078751 & $52 *$ & $\begin{array}{l}\text { HR+ } \\
\text { HER2- } \\
\text { (high risk) }\end{array}$ & Adjuvant & Ribociclib + ET vs placebo + ET & IDFS \\
\hline monarchE & 03155997 & 3580 & $\begin{array}{l}\text { HR+ } \\
\text { HER2- } \\
\text { (high risk) }\end{array}$ & Adjuvant & Abemaciclib + ET vs ET & IDFS \\
\hline \multicolumn{7}{|l|}{ Phase II } \\
\hline NEOBLC & 03283384 & 100 & HR+ HER2- & $\begin{array}{l}\text { Neo-adjuvant, } \\
\text { stage II or III }\end{array}$ & $\begin{array}{l}\text { Al followed by chemotherapy vs } \\
\text { Al + ribociclib }\end{array}$ & CCCA \\
\hline neoMONARCH & 02441946 & $224 *$ & $\mathrm{HR}+\mathrm{HER} 2-$ & Neo-adjuvant & $\begin{array}{l}\text { Al vs abemaciclib vs } \\
\text { Al + abemaciclib }\end{array}$ & $\begin{array}{l}\text { Change in } \\
\text { Ki67 } \\
\text { expression }\end{array}$ \\
\hline PALLET & 02296801 & 306 & HR+ HER2- & Neo-adjuvant & $\begin{array}{l}\text { Al vs } \mathrm{Al} \text { then } \mathrm{Al}+\text { palbociclib vs } \\
\text { palbociclib then } \mathrm{Al}+\text { palbociclib } \\
\text { vs } \mathrm{Al}+\text { palbociclib }\end{array}$ & $\begin{array}{l}\text { Change in } \\
\text { Ki67 } \\
\text { expression } \\
\text { and cCR }\end{array}$ \\
\hline
\end{tabular}

Al, aromatase inhibitor; CCCA, complete cell cycle arrest; cCR, clinical complete response; ET, endocrine therapy; HR, hormone receptor; IDFS, invasive disease-free survival; pCR, pathological complete response. * actual enrolment

representing another potential therapeutic combination for this class of drug (Goel et al. 2017, Deng et al. 2018).

\section{The future of CDK4/6 inhibitor use and resistance in ER+ breast cancer}

The addition of CDK/6 inhibitors into contemporary treatment algorithms for advanced ER+ breast cancer represents a renaissance for the most common subtype of breast cancer and represents the most significant advance in the last decade. While CDK4/6 inhibitors have changed the natural history of ER+ breast cancer by prolonging the PFS, when used in the metastatic context, disease progression and the emergence of resistance is inevitable. As they become standard therapy, combined resistance to endocrine and CDK4/6 inhibitor therapy represents the next wave of clinical challenge to face the breast cancer community. To benefit these patients, we need a detailed mechanistic understanding of CDK4/6 inhibitor resistance in an endocrine sensitive and resistant setting.

The full potential of CDK4/6 inhibitors has yet to be realised, and trials are currently underway to expand its use to other breast cancer subtypes, earlier stages of disease and other cancers. With the success of CDK4/6 inhibitors in advanced ER+ breast cancer, it is now logically being evaluated in early stage ER+ breast cancer. A series of phase II and phase III adjuvant and neoadjuvant trials with CDK4/6 inhibitors are currently underway (NEOLBC (NCT03283384), neoMONARCH (NCT02441946), PALLET (NCT02296801), SAFIA (NCT03447132), monarchE (NCT03155997) and PALLAS (NCT02513394)) (Table 4). The exclusion of HER2+ patients is also being reassessed after the positive results of the abemaciclib monotherapy trial (Patnaik et al. 2016), where $36 \%$ (4/11) of ER+ HER2+ patients showed a response compared to $28 \%$ (7/25) of ER+ HER2- patients, and several trials such as PATINA (NCT02947685), PATRICIA (NCT02448420) and monarcHER (NCT02675231) are evaluating combinations of CDK4/6 inhibitors, anti-HER2 (trastuzumab, pertuzumab) and endocrine therapy. These emerging treatment scenarios will have different genetic backgrounds and selective drug pressures, potentially giving rise to unique resistance mechanisms in each treatment type. (c) 2019 Society for Endocrinology Published by Bioscientifica Ltd. Printed in Great Britain 


\section{Declaration of interest}

The authors declare that there is no conflict of interest that could be perceived as prejudicing the impartiality of this review.

\section{Funding}

$E L$ and $N P$ receive research funding from Novartis Oncology and Bayer. $E$ $L$ and C E C are supported by the National Breast Cancer Foundation. E L is supported by the Love Your Sister.

\section{Author contribution statement}

$\mathrm{N}$ Portman, S Alexandrou, E Lim and C E Caldon contributed equally to this work.

\section{References}

Anders L, Ke N, Hydbring P, Choi YJ, Widlund HR, Chick JM, Zhai H, Vidal M, Gygi SP, Braun P, et al. 2011 A systematic screen for CDK4/6 substrates links FOXM1 phosphorylation to senescence suppression in cancer cells. Cancer Cell 20 620-634. (https://doi. org/10.1016/j.ccr.2011.10.001)

Asghar U, Witkiewicz AK, Turner NC \& Knudsen ES 2015 The history and future of targeting cyclin-dependent kinases in cancer therapy. Nature Reviews Drug Discovery 14 130-146. (https://doi.org/10.1038/ nrd4504)

Bagegni N, Thomas S, Liu N, Luo J, Hoog J, Northfelt DW, Goetz MP, Forero A, Bergqvist M, Karen J, et al. 2017 Serum thymidine kinase 1 activity as a pharmacodynamic marker of cyclin-dependent kinase 4/6 inhibition in patients with early-stage breast cancer receiving neoadjuvant palbociclib. Breast Cancer Research 19 123. (https://doi. org/10.1186/s13058-017-0913-7)

Baselga J, Campone M, Piccart M, Burris HA 3rd, Rugo HS, Sahmoud T, Noguchi S, Gnant M, Pritchard KI, Lebrun F, et al. 2012 Everolimus in postmenopausal hormone-receptor-positive advanced breast cancer. New England Journal of Medicine 366 520-529. (https://doi. org/10.1056/NEJMoa1109653)

Baselga J, Im SA, Iwata H, Cortes J, De Laurentiis M, Jiang Z, Arteaga CL, Jonat W, Clemons M, Ito Y, et al. 2017 Buparlisib plus fulvestrant versus placebo plus fulvestrant in postmenopausal, hormone receptor-positive, HER2-negative, advanced breast cancer (BELLE-2): a randomised, double-blind, placebo-controlled, phase 3 trial. Lancet Oncology 18 904-916. (https://doi.org/10.1016/S1470-2045(17)303765)

Bollard J, Miguela V, Ruiz de Galarreta M, Venkatesh A, Bian CB, Roberto MP, Tovar V, Sia D, Molina-Sanchez P, Nguyen CB, et al. 2017 Palbociclib (PD-0332991), a selective CDK4/6 inhibitor, restricts tumour growth in preclinical models of hepatocellular carcinoma. Gut 66 1286-1296. (https://doi.org/10.1136/gutjnl-2016-312268)

Burkhart DL \& Sage J 2008 Cellular mechanisms of tumour suppression by the retinoblastoma gene. Nature Reviews Cancer 8 671-682. (https://doi.org/10.1038/nrc2399)

Caldon CE, Sergio CM, Schutte J, Boersma MN, Sutherland RL, Carroll JS \& Musgrove EA 2009 Estrogen regulation of cyclin E2 requires cyclin D1 but not c-Myc. Molecular and Cellular Biology 29 4623-4639. (https://doi.org/10.1128/MCB.00269-09)

Caldon CE, Sergio CM, Kang J, Muthukaruppan A, Boersma MN, Stone A, Barraclough J, Lee CS, Black MA, Miller LD, et al. 2012 Cyclin E2 overexpression is associated with endocrine resistance but not insensitivity to CDK2 inhibition in human breast cancer cells. Molecular Cancer Therapeutics 11 1488-1499. (https://doi. org/10.1158/1535-7163.MCT-11-0963)
Castellano D, Rubio C, López-Calderón F, Segovia C, Dueñas M, Martinez-Fernández M, Otero I, Manneh R, De Velasco G \& Paramio J 2016 Cdk4/6 inhibitor activity in metastatic bladder cancer cell lines is independently of RB1 status. Annals of Oncology 27 ix1-ix8. (https://doi.org/10.1093/annonc/mdw573.007)

Chen P, Lee NV, Hu W, Xu M, Ferre RA, Lam H, Bergqvist S, Solowiej J, Diehl W, He YA, et al. 2016 Spectrum and degree of CDK drug interactions predicts clinical performance. Molecular Cancer Therapeutics 15 2273-2281. (https://doi.org/10.1158/1535-7163.MCT16-0300)

Chou A, Froio D, Nagrial AM, Parkin A, Murphy KJ, Chin VT, Wohl D, Steinmann A, Stark R, Drury A, et al. 2017 Tailored first-line and second-line CDK4-targeting treatment combinations in mouse models of pancreatic cancer. Gut [epub]. (https://doi.org/10.1136/ gutjnl-2017-315144)

Ciriello G, Gatza ML, Beck AH, Wilkerson MD, Rhie SK, Pastore A, Zhang H, McLellan M, Yau C, Kandoth C, et al. 2015 Comprehensive molecular portraits of invasive lobular breast cancer. Cell 163 506-519. (https://doi.org/10.1016/j.cell.2015.09.033)

Condorelli R, Spring L, O'Shaughnessy J, Lacroix L, Bailleux C, Scott V, Dubois J, Nagy RJ, Lanman RB, Iafrate AJ, et al. 2018 Polyclonal RB1 mutations and acquired resistance to CDK 4/6 inhibitors in patients with metastatic breast cancer. Annals of Oncology 29 640-645. (https://doi.org/10.1093/annonc/mdx784)

Cousins EM, Goldfarb D, Yan F, Roques J, Darr D, Johnson GL \& Major MB 2018 Competitive kinase enrichment proteomics reveals that abemaciclib inhibits GSK3beta and activates WNT signaling. Molecular Cancer Research 16 333-344. (https://doi.org/10.1158/15417786.MCR-17-0468)

Cristofanilli M, Turner NC, Bondarenko I, Ro J, Im SA, Masuda N, Colleoni M, DeMichele A, Loi S, Verma S, et al. 2016 Fulvestrant plus palbociclib versus fulvestrant plus placebo for treatment of hormone-receptor-positive, HER2-negative metastatic breast cancer that progressed on previous endocrine therapy (PALOMA-3): final analysis of the multicentre, double-blind, phase 3 randomised controlled trial. Lancet Oncology 17 425-439. (https://doi. org/10.1016/S1470-2045(15)00613-0)

Cruz MR, Limentani K, Taxter T, Santa-Maria CA, Behdad A, Gradishar WJ, Nagy RJ \& Cristofanilli M 2018 Patterns of genomic alterations in ER-positive advanced breast cancer patients treated with CDK4/6 inhibitors [abstract]. In: Proceedings of the 2017. San Antonio Breast Cancer Symposium. Cancer Research 78 Abstract nr PD4-05. (https://doi.org/10.1158/1538-7445.SABCS17-PD4-05)

Dean JL, McClendon AK, Hickey TE, Butler LM, Tilley WD, Witkiewicz AK \& Knudsen ES 2012 Therapeutic response to CDK4/6 inhibition in breast cancer defined by ex vivo analyses of human tumors. Cell Cycle 11 2756-2761. (https://doi.org/10.4161/cc.21195)

DeMichele A, Clark AS, Tan KS, Heitjan DF, Gramlich K, Gallagher M, Lal P, Feldman M, Zhang P, Colameco C, et al. 2015 CDK 4/6 inhibitor palbociclib (PD0332991) in Rb+ advanced breast cancer: phase II activity, safety, and predictive biomarker assessment. Clinical Cancer Research 21 995-1001. (https://doi.org/10.1158/1078-0432. CCR-14-2258)

Deng J, Wang ES, Jenkins RW, Li S, Dries R, Yates K, Chhabra S, Huang W, Liu H, Aref AR, et al. 2018 CDK4/6 inhibition augments antitumor immunity by enhancing T-cell activation. Cancer Discovery 8 216-233. (https://doi.org/10.1158/2159-8290.CD-17-0915)

Dhakal A, Matthews CM, Levine EG, Salerno KE, Zhang F, Takabe K, Early AP, Edge SB, O'Connor T, Khoury T, et al. 2018 Efficacy of palbociclib combinations in hormone receptor-positive metastatic breast cancer patients after prior everolimus treatment. Clinical Breast Cancer [epub]. (https://doi.org/10.1016/j.clbc.2018.04.015)

Dickler MN, Tolaney SM, Rugo HS, Cortes J, Dieras V, Patt D, Wildiers H, Hudis CA, O'Shaughnessy J, Zamora E, et al. 2017 MONARCH 1, a phase ii study of abemaciclib, a CDK4 and CDK6 inhibitor, as a single agent, in patients with refractory HR(+)/HER2(-) metastatic 
breast cancer. Clinical Cancer Research 23 5218-5224. (https://doi. org/10.1158/1078-0432.CCR-17-0754)

Doostan I, Karakas C, Kohansal M, Low KH, Ellis MJ, Olson JA Jr, Suman VJ, Hunt KK, Moulder SL \& Keyomarsi K 2017 Cytoplasmic cyclin E mediates resistance to aromatase inhibitors in breast cancer. Clinical Cancer Research 23 7288-7300. (https://doi. org/10.1158/1078-0432.CCR-17-1544)

du Rusquec P, Palpacuer C, Campion L, Patsouris A, Augereau P, Gourmelon C, Robert M, Dumas L, Caroline F, Campone M, et al. 2018 Efficacy of palbociclib plus fulvestrant after everolimus in hormone receptor-positive metastatic breast cancer. Breast Cancer Research and Treatment 168 559-566. (https://doi.org/10.1007/ s10549-017-4623-8)

Early Breast Cancer Trialists' Collaborative Group 2015 Aromatase inhibitors versus tamoxifen in early breast cancer: patient-level meta-analysis of the randomised trials. Lancet 386 1341-1352. (https://doi.org/10.1016/S0140-6736(15)61074-1)

Elvin JA, Gay LM, Ort R, Shuluk J, Long J, Shelley L, Lee R, Chalmers ZR, Frampton GM, Ali SM, et al. 2017 Clinical benefit in response to palbociclib treatment in refractory uterine leiomyosarcomas with a common CDKN2A alteration. Oncologist 22 416-421. (https://doi.org/10.1634/theoncologist.2016-0310)

Ertel A, Dean JL, Rui H, Liu C, Witkiewicz AK, Knudsen KE \& Knudsen ES 2010 RB-pathway disruption in breast cancer: differential association with disease subtypes, disease-specific prognosis and therapeutic response. Cell Cycle 9 4153-4163. (https:// doi.org/10.4161/cc.9.20.13454)

Filmus J, Robles AI, Shi W, Wong MJ, Colombo LL \& Conti CJ 1994 Induction of cyclin D1 overexpression by activated ras. Oncogene 9 3627-3633.

Finn RS, Dering J, Conklin D, Kalous O, Cohen DJ, Desai AJ, Ginther C, Atefi M, Chen I, Fowst C, et al. 2009 PD 0332991, a selective cyclin D kinase 4/6 inhibitor, preferentially inhibits proliferation of luminal estrogen receptor-positive human breast cancer cell lines in vitro. Breast Cancer Research 11 R77. (https://doi.org/10.1186/ bcr2419)

Finn RS, Crown JP, Lang I, Boer K, Bondarenko IM, Kulyk SO, Ettl J, Patel R, Pinter T, Schmidt M, et al. 2015 The cyclin-dependent kinase $4 / 6$ inhibitor palbociclib in combination with letrozole versus letrozole alone as first-line treatment of oestrogen receptor-positive, HER2-negative, advanced breast cancer (PALOMA-1/TRIO-18): a randomised phase 2 study. Lancet Oncology 16 25-35. (https://doi. org/10.1016/S1470-2045(14)71159-3)

Finn RS, Martin M, Rugo HS, Jones S, Im SA, Gelmon K, Harbeck N, Lipatov ON, Walshe JM, Moulder S, et al. 2016 Palbociclib and letrozole in advanced breast cancer. New England Journal of Medicine 375 1925-1936. (https://doi.org/10.1056/NEJMoa1607303)

Formisano L, Lu Y, Jansen VM, Bauer JA, Hanker A, Gonzalez EP, Lee KM, Nixon MJ, Guerrero-Zotano AL, Schwarz LJ, et al. 2018 Gain-offunction kinase library screen identifies FGFR1 amplification as a mechanism of resistance to antiestrogens and CDK4/6 inhibitors in ER+ breast cancer [abstract]. In: Proceedings of the 2017 San Antonio Breast Cancer Symposium. Cancer Research 78 Abstract nr GS6-05. (https://doi.org/10.1158/1538-7445.SABCS17-GS6-05)

Francis AM, Alexander A, Liu Y, Vijayaraghavan S, Low KH, Yang D, Bui T, Somaiah N, Ravi V, Keyomarsi K, et al. 2017 CDK4/6 inhibitors sensitize Rb-positive sarcoma cells to Wee1 kinase inhibition through reversible cell-cycle arrest. Molecular Cancer Therapeutics 16 1751-1764. (https://doi.org/10.1158/1535-7163.MCT17-0040)

Franco J, Witkiewicz AK \& Knudsen ES 2014 CDK4/6 inhibitors have potent activity in combination with pathway selective therapeutic agents in models of pancreatic cancer. Oncotarget 5 6512-6525. (https://doi.org/10.18632/oncotarget.2270)

Fribbens C, O'Leary B, Kilburn L, Hrebien S, Garcia-Murillas I, Beaney M, Cristofanilli M, Andre F, Loi S, Loibl S, et al. 2016 Plasma
ESR1 mutations and the treatment of estrogen receptor-positive advanced breast cancer. Journal of Clinical Oncology 34 2961-2968. (https://doi.org/10.1200/JCO.2016.67.3061)

Fry DW, Harvey PJ, Keller PR, Elliott WL, Meade M, Trachet E, Albassam M, Zheng X, Leopold WR, Pryer NK, et al. 2004 Specific inhibition of cyclin-dependent kinase 4/6 by PD 0332991 and associated antitumor activity in human tumor xenografts. Molecular Cancer Therapeutics 3 1427-1438.

Gelbert LM, Cai S, Lin X, Sanchez-Martinez C, Del Prado M, Lallena MJ, Torres R, Ajamie RT, Wishart GN, Flack RS, et al. 2014 Preclinical characterization of the CDK4/6 inhibitor LY2835219: in-vivo cell cycle-dependent/independent anti-tumor activities alone/in combination with gemcitabine. Investigational New Drugs 32 825-837. (https://doi.org/10.1007/s10637-014-0120-7)

Goel S, DeCristo MJ, Watt AC, BrinJones H, Sceneay J, Li BB, Khan N, Ubellacker JM, Xie S, Metzger-Filho O, et al. 2017 CDK4/6 inhibition triggers anti-tumour immunity. Nature 548 471-475. (https://doi. org/10.1038/nature23465)

Goetz MP, Toi M, Campone M, Sohn J, Paluch-Shimon S, Huober J, Park IH, Tredan O, Chen SC, Manso L, et al. 2017 MONARCH 3: abemaciclib as initial therapy for advanced breast cancer. Journal of Clinical Oncology 35 3638-3646. (https://doi.org/10.1200/ JCO.2017.75.6155)

Gong X, Litchfield LM, Webster Y, Chio LC, Wong SS, Stewart TR, Dowless M, Dempsey J, Zeng Y, Torres R, et al. 2017 Genomic aberrations that activate D-type cyclins are associated with enhanced sensitivity to the CDK4 and CDK6 inhibitor abemaciclib. Cancer Cell 32 761.e766-776.e766. (https://doi.org/10.1016/j.ccell.2017.11.006)

Guan X, LaPak KM, Hennessey RC, Yu CY, Shakya R, Zhang J \& Burd CE 2017 Stromal senescence by prolonged CDK4/6 inhibition potentiates tumor growth. Molecular Cancer Research 15 237-249. (https://doi.org/10.1158/1541-7786.MCR-16-0319)

Guerrero-Zotano AL, Stricker TP, Formisano L, Hutchinson KE, Stover DG, Lee KM, Schwarz LJ, Giltnane JM, Estrada MV, Jansen VM, et al. $2018 \mathrm{ER}(+)$ breast cancers resistant to prolonged neoadjuvant letrozole exhibit an E2F4 transcriptional program sensitive to CDK4/6 inhibitors. Clinical Cancer Research $\mathbf{2 4}$ 2517-2529. (https://doi.org/10.1158/1078-0432.CCR-17-2904)

Hanahan D \& Weinberg RA 2011 Hallmarks of cancer: the next generation. Cell 144 646-674. (https://doi.org/10.1016/j. cell.2011.02.013)

Haricharan S, Punturi N, Singh P, Holloway KR, Anurag M, Schmelz J, Schmidt C, Lei JT, Suman V, Hunt K, et al. 2017 Loss of MutL disrupts CHK2-dependent cell-cycle control through CDK4/6 to promote intrinsic endocrine therapy resistance in primary breast cancer. Cancer Discovery 7 1168-1183. (https://doi.org/10.1158/21598290.CD-16-1179)

Herrera-Abreu MT, Palafox M, Asghar U, Rivas MA, Cutts RJ, GarciaMurillas I, Pearson A, Guzman M, Rodriguez O, Grueso J, et al. 2016 Early adaptation and acquired resistance to CDK4/6 inhibition in estrogen receptor-positive breast cancer. Cancer Research 76 2301-2313. (https://doi.org/10.1158/0008-5472.CAN-15-0728)

Hortobagyi GN, Stemmer SM, Burris HA, Yap YS, Sonke GS, PaluchShimon S, Campone M, Blackwell KL, Andre F, Winer EP, et al. 2016 Ribociclib as first-line therapy for HR-positive, advanced breast cancer. New England Journal of Medicine 375 1738-1748. (https://doi. org/10.1056/NEJMoa1609709)

Hortobagyi GN, Stemmer SM, Burris HA, Yap YS, Sonke GS, PaluchShimon S, Campone M, Petrakova K, Blackwell KL, Winer EP, et al. 2018 Updated results from MONALEESA-2, a phase III trial of firstline ribociclib plus letrozole versus placebo plus letrozole in hormone receptor-positive, HER2-negative advanced breast cancer. Annals of Oncology 29 1541-1547. (https://doi.org/10.1093/annonc/ mdy155)

Hunt KK, Karakas C, Ha MJ, Biernacka A, Yi M, Sahin AA, Adjapong O, Hortobagyi GN, Bondy M, Thompson P, et al. 2017 Cytoplasmic https://erc.bioscientifica.com

https://doi.org/10.1530/ERC-18-0317
(C) 2019 Society for Endocrinology Published by Bioscientifica Ltd. Printed in Great Britain 
cyclin E predicts recurrence in patients with breast cancer. Clinical Cancer Research 23 2991-3002. (https://doi.org/10.1158/1078-0432. CCR-16-2217)

Infante JR, Shapiro G, Witteveen P, Gerecitano JF, Ribrag V, Chugh R, Issa I, Chakraborty A, Matano A \& Zhao X 2014 A phase I study of the single-agent CDK4/6 inhibitor LEE011 in pts with advanced solid tumors and lymphomas [abstract]. Journal of Clinical Oncology 32 2528. (https://doi.org/10.1200/jco.2014.32.15_suppl.2528)

Jansen VM, Bhola NE, Bauer JA, Formisano L, Lee KM, Hutchinson KE, Witkiewicz AK, Moore PD, Estrada MV, Sanchez V, et al. 2017 Kinome-wide RNA interference screen reveals a role for PDK1 in acquired resistance to CDK4/6 inhibition in ER-positive breast cancer. Cancer Research 77 2488-2499. (https://doi.org/10.1158/00085472.CAN-16-2653)

Jeselsohn R, Yelensky R, Buchwalter G, Frampton G, Meric-Bernstam F, Gonzalez-Angulo AM, Ferrer-Lozano J, Perez-Fidalgo JA, Cristofanilli M, Gomez H, et al. 2014 Emergence of constitutively active estrogen receptor-alpha mutations in pretreated advanced estrogen receptor-positive breast cancer. Clinical Cancer Research 20 1757-1767. (https://doi.org/10.1158/1078-0432.CCR-13-2332)

Johnson SF, Cruz C, Greifenberg AK, Dust S, Stover DG, Chi D, Primack B, Cao S, Bernhardy AJ, Coulson R, et al. 2016 CDK12 inhibition reverses de novo and acquired parp inhibitor resistance in BRCA wild-type and mutated models of triple-negative breast cancer. Cell Reports 17 2367-2381. (https://doi.org/10.1016/j. celrep.2016.10.077)

Kalra S, Joshi G, Munshi A \& Kumar R 2017 Structural insights of cyclin dependent kinases: implications in design of selective inhibitors. Eur J Med Chem 142 424-458. (https://doi.org/10.1016/j. ejmech.2017.08.071)

Karakas C, Biernacka A, Bui T, Sahin AA, Yi M, Akli S, Schafer J, Alexander A, Adjapong O, Hunt KK, et al. 2016 Cytoplasmic cyclin E and phospho-cyclin-dependent kinase 2 Are biomarkers of aggressive breast cancer. Am J Pathol 186 1900-1912. (https://doi.org/10.1016/j. ajpath.2016.02.024)

Karasic TB, O'Hara MH, Teitelbaum UR, Damjanov N, Giantonio BJ, d'Entremont TS, Gallagher M, Zhang PJ \& O'Dwyer PJ 2018 Phase II trial of palbociclib in patients with advanced esophageal or gastric cancer. Journal of Clinical Oncology 36 68-68. (https://doi. org/10.1200/JCO.2018.36.4_suppl.68)

Kassem L, Shohdy KS, Lasheen S, Abdel-Rahman O \& Bachelot T 2018 Hematological adverse effects in breast cancer patients treated with cyclin-dependent kinase 4 and 6 inhibitors: a systematic review and meta-analysis. Breast Cancer 25 17-27. (https://doi.org/10.1007/ s12282-017-0818-4)

Kato J, Matsushime H, Hiebert SW, Ewen ME \& Sherr CJ 1993 Direct binding of cyclin $\mathrm{D}$ to the retinoblastoma gene product $(\mathrm{pRb})$ and $\mathrm{pRb}$ phosphorylation by the cyclin D-dependent kinase CDK4. Genes Dev 7 331-342. (https://doi.org/10.1101/gad.7.3.331)

Kim WY \& Sharpless NE 2006 The regulation of INK4/ARF in cancer and aging. Cell 127 265-275. (https://doi.org/10.1016/j. cell.2006.10.003)

Knudsen ES \& Witkiewicz AK 2016 Defining the transcriptional and biological response to CDK4/6 inhibition in relation to ER+/HER2breast cancer. Oncotarget 7 69111-69123. (https://doi.org/10.18632/ oncotarget.11588)

Konecny GE, Winterhoff B, Kolarova T, Qi J, Manivong K, Dering J, Yang G, Chalukya M, Wang HJ, Anderson L, et al. 2011 Expression of p16 and retinoblastoma determines response to CDK4/6 inhibition in ovarian cancer. Clinical Cancer Research 17 1591-1602. (https://doi.org/10.1158/1078-0432.CCR-10-2307)

Lapenna S \& Giordano A 2009 Cell cycle kinases as therapeutic targets for cancer. Nature Reviews Drug Discovery 8 547-566. (https://doi. org/10.1038/nrd2907)

Lenjisa JL, Tadesse S, Khair NZ, Kumarasiri M, Yu M, Albrecht H, Milne R \& Wang S 2017 CDK5 in oncology: recent advances and future prospects. Future Med Chem 9 1939-1962. (https://doi org/10.4155/fmc-2017-0097)

Li Y, Guo Q, Zhang C, Huang Z, Wang T, Wang X, Wang X, Xu G, Liu Y, Yang S, et al. 2017 Discovery of a highly potent, selective and novel CDK9 inhibitor as an anticancer drug candidate. Bioorg Med Chem Lett 27 3231-3237. (https://doi.org/10.1016/j.bmcl.2017.06.041)

Malorni L, Piazza S, Ciani Y, Guarducci C, Bonechi M, Biagioni C, Hart CD, Verardo R, Di Leo A \& Migliaccio I 2016 A gene expression signature of retinoblastoma loss-of-function is a predictive biomarker of resistance to palbociclib in breast cancer cell lines and is prognostic in patients with ER positive early breast cancer. Oncotarget 7 68012-68022. (https://doi.org/10.18632/oncotarget.12010)

Malorni L, Curigliano G, Minisini AM, Cinieri S, Tondini CA, D’Hollander K, Arpino G, Bernardo A, Martignetti A, Criscitiello C, et al. 2018 Palbociclib as single agent or in combination with the endocrine therapy received before disease progression for estrogen receptor-positive, HER2-negative metastatic breast cancer: TREnd trial. Annals of Oncology 29 1748-1754. (https://doi.org/10.1093/ annonc/mdy214)

Malumbres M 2014 Cyclin-dependent kinases. Genome Biol 15122. (https://doi.org/10.1186/gb4184)

Mamiya H, Tahara RK, Tolaney SM, Choudhry NK \& Najafzadeh M 2017 Cost-effectiveness of palbociclib in hormone receptor-positive advanced breast cancer. Annals of Oncology 28 1825-1831. (https:// doi.org/10.1093/annonc/mdx201)

Mao P, Kusiel J, Cohen O \& Wagle N 2018 The role of FGF/FGFR axis in resistance to SERDs and CDK4/6 inhibitors in ER+ breast cancer [abstract]. In: Proceedings of the 2017 San Antonio Breast Cancer Symposium. Cancer Research 78 Abstract nr PD4-01. (https://doi. org/10.1158/1538-7445.SABCS17-PD4-01)

Martin L-A, Pancholi S, Ribas R, Gao Q, Simigdala N, NikitorowiczBuniak J, Johnston SR \& Dowsett M 2017 Resistance to palbociclib depends on multiple targetable mechanisms highlighting the potential of drug holidays and drug switching to improve therapeutic outcome [abstract]. In: Proceedings of the 2016.z San Antonio Breast Cancer Symposium. Cancer Research 77 Abstract nr P3-03-09. (https://doi.org/10.1158/1538-7445.SABCS16-P3-03-09)

Michaloglou C, Crafter C, Siersbaek R, Delpuech O, Curwen JO, Carnevalli LS, Staniszewska AD, Polanska UM, Cheraghchi-Bashi A, Lawson M, et al. 2018 Combined inhibition of mTOR and CDK4/6 is required for optimal blockade of E2F function and long-term growth inhibition in estrogen receptor-positive breast cancer. Molecular Cancer Therapeutics 17 908-920. (https://doi.org/10.1158/1535-7163. MCT-17-0537)

Michaud K, Solomon DA, Oermann E, Kim JS, Zhong WZ, Prados MD, Ozawa T, James CD \& Waldman T 2010 Pharmacologic inhibition of cyclin-dependent kinases 4 and 6 arrests the growth of glioblastoma multiforme intracranial xenografts. Cancer Research 70 3228-3238. (https://doi.org/10.1158/0008-5472.CAN-09-4559)

Miettinen TP, Peltier J, Hartlova A, Gierlinski M, Jansen VM, Trost M \& Bjorklund M 2018 Thermal proteome profiling of breast cancer cells reveals proteasomal activation by CDK4/6 inhibitor palbociclib. EMBO J 37 e98359. (https://doi.org/10.15252/embj.201798359)

Musgrove EA \& Sutherland RL 2009 Biological determinants of endocrine resistance in breast cancer. Nature Reviews Cancer 9 631-643. (https://doi.org/10.1038/nrc2713)

Musgrove EA, Caldon CE, Barraclough J, Stone A \& Sutherland RL 2011 Cyclin D as a therapeutic target in cancer. Nature Reviews Cancer 11 558-572. (https://doi.org/10.1038/nrc3090)

O’Brien NA, Di Tomaso E, Ayala R, Tong L, Issakhanian S, Linnartz R, Finn RS, Hirawat S \& Slamon DJ 2014 In vivo efficacy of combined targeting of CDK4/6, ER and PI3K signaling in ER+ breast cancer. [abstract]. In: Proceedings of the 105th Annual Meeting of the American Association for Cancer Research; 2014 Apr 5-9; San Diego, CA. Philadelphia (PA): AACR. Cancer Research 74 Abstract 4756. (https://doi.org/10.1158/1538-7445.AM2014-4756) 
Olanich ME, Sun W, Hewitt SM, Abdullaev Z, Pack SD \& Barr FG 2015 CDK4 amplification reduces sensitivity to CDK4/6 inhibition in fusion-positive rhabdomyosarcoma. Clinical Cancer Research $\mathbf{2 1}$ 4947-4959. (https://doi.org/10.1158/1078-0432.CCR-14-2955)

Pal SK, Ali SM, Ross J, Choueiri TK \& Chung JH 2017 Exceptional response to palbociclib in metastatic collecting duct carcinoma bearing a CDKN2A homozygous deletion. JCO Precision Oncology 1 1-5. (https://doi.org/10.1200/PO.17.00017)

Paternot S, Colleoni B, Bisteau X \& Roger PP 2014 The CDK4/CDK6 inhibitor PD0332991 paradoxically stabilizes activated cyclin D3-CDK4/6 complexes. Cell Cycle 13 2879-2888. (https://doi.org/10. 4161/15384101.2014.946841)

Patnaik A, Rosen LS, Tolaney SM, Tolcher AW, Goldman JW, Gandhi L, Papadopoulos KP, Beeram M, Rasco DW, Hilton JF, et al. 2016 Efficacy and safety of abemaciclib, an inhibitor of CDK4 and CDK6, for patients with breast cancer, non-small cell lung cancer, and other solid tumors. Cancer Discovery 6 740-753. (https://doi. org/10.1158/2159-8290.CD-16-0095)

Peyressatre M, Prevel C, Pellerano M \& Morris MC 2015 Targeting cyclin-dependent kinases in human cancers: from small molecules to Peptide inhibitors. Cancers 7 179-237. (https://doi.org/10.3390/ cancers7010179)

Philip S, Kumarasiri M, Teo T, Yu M \& Wang S 2018 Cyclin-dependent kinase 8: a new hope in targeted cancer therapy? J Med Chem 61 5073-5092. (https://doi.org/10.1021/acs.jmedchem.7b00901)

Prall OW, Sarcevic B, Musgrove EA, Watts CK \& Sutherland RL 1997 Estrogen-induced activation of Cdk4 and Cdk2 during G1-S phase progression is accompanied by increased cyclin D1 expression and decreased cyclin-dependent kinase inhibitor association with cyclin E-Cdk2. J Biol Chem 272 10882-10894. (https://doi.org/10.1074/ jbc.272.16.10882)

Raspe E, Coulonval K, Pita JM, Paternot S, Rothe F, Twyffels L, Brohee S, Craciun L, Larsimont D, Kruys V, et al. 2017 CDK4 phosphorylation status and a linked gene expression profile predict sensitivity to palbociclib. EMBO Mol Med 9 1052-1066. (https://doi.org/10.15252/ emmm.201607084)

Raub TJ, Wishart GN, Kulanthaivel P, Staton BA, Ajamie RT, Sawada GA, Gelbert LM, Shannon HE, Sanchez-Martinez C \& De Dios A 2015 Brain exposure of two selective dual CDK4 and CDK6 inhibitors and the antitumor activity of CDK4 and CDK6 inhibition in combination with temozolomide in an intracranial glioblastoma xenograft. Drug Metab Dispos 43 1360-1371. (https://doi. org/10.1124/dmd.114.062745)

Romano G, Chen PL, Song P, McQuade JL, Liang RJ, Liu M, Roh W, Duose DY, Carapeto FCL, Li J, et al. 2018 A preexisting rare PIK3CA(E545K) subpopulation confers clinical resistance to MEK plus CDK4/6 inhibition in NRAS melanoma and is dependent on S6K1 signaling. Cancer Discovery 8 556-567. (https://doi. org/10.1158/2159-8290.CD-17-0745)

Scheicher R, Hoelbl-Kovacic A, Bellutti F, Tigan AS, Prchal-Murphy M, Heller G, Schneckenleithner C, Salazar-Roa M, Zochbauer-Muller S, Zuber J, et al. 2015 CDK6 as a key regulator of hematopoietic and leukemic stem cell activation. Blood 125 90-101. (https://doi. org/10.1182/blood-2014-06-584417)

Schiavon G, Hrebien S, Garcia-Murillas I, Cutts RJ, Pearson A, Tarazona N, Fenwick K, Kozarewa I, Lopez-Knowles E, Ribas R, et al. 2015 Analysis of ESR1 mutation in circulating tumor DNA demonstrates evolution during therapy for metastatic breast cancer. Sci Transl Med 7 313ra182. (https://doi.org/10.1126/scitranslmed. aac7551)

Shah M, Nunes MR \& Stearns V 2018 CDK4/6 inhibitors: game changers in the management of hormone receptor-positive advanced breast cancer? Oncology 32 216-222.

Shapiro GI 2006 Cyclin-dependent kinase pathways as targets for cancer treatment. Journal of Clinical Oncology 24 1770-1783. (https://doi. org/10.1200/JCO.2005.03.7689)
Sharpless NE \& Sherr CJ 2015 Forging a signature of in vivo senescence. Nature Reviews Cancer 15 397-408. (https://doi. org/10.1038/nrc3960)

Shee K, Hinds JW, Yang W, Hampsch RA, Patel K, Varn FS, Cheng C, Jenkins NP, Kettenbach AN, Demidenko E, et al. 2018 A microenvironment secretome screen reveals FGF2 as a mediator of resistance to anti-estrogens and PI3K/mTOR pathway inhibitors in ER+ breast cancer [abstract]. In: Proceedings of the 2017 San Antonio Breast Cancer Symposium. Cancer Research 78 Abstract nr PD4-08. (https://doi.org/10.1158/1538-7445.SABCS17-PD4-08)

Sheppard KE \& McArthur GA 2013 The cell-cycle regulator CDK4: an emerging therapeutic target in melanoma. Clinical Cancer Research 19 5320-5328. (https://doi.org/10.1158/1078-0432.CCR-13-0259)

Sherr CJ 1996 Cancer cell cycles. Science 274 1672-1677. (https://doi. org/10.1126/science.274.5293.1672)

Sherr CJ \& Roberts JM 1999 CDK inhibitors: positive and negative regulators of G1-phase progression. Genes Dev 13 1501-1512. (https://doi.org/10.1101/gad.13.12.1501)

Shohdy KS, Lasheen S, Kassem L \& Abdel-Rahman O 2017 Gastrointestinal adverse effects of cyclin-dependent kinase 4 and 6 inhibitors in breast cancer patients: a systematic review and metaanalysis. Ther Adv Drug Saf 8 337-347. (https://doi. org/10.1177/2042098617722516)

Slamon DJ, Neven P, Chia S, Fasching PA, De Laurentiis M, Im SA, Petrakova K, Bianchi GV, Esteva FJ, Martin M, et al. 2018 Phase III randomized study of ribociclib and fulvestrant in hormone receptorpositive, human epidermal growth factor receptor 2-negative advanced breast cancer: MONALEESA-3. Journal of Clinical Oncology 36 2465-2472. (https://doi.org/10.1200/JCO.2018.78.9909)

Sledge GW Jr, Toi M, Neven P, Sohn J, Inoue K, Pivot X, Burdaeva O, Okera M, Masuda N, Kaufman PA, et al. 2017 MONARCH 2: abemaciclib in combination with fulvestrant in women with $\mathrm{HR}+$ / HER2- advanced breast cancer who had progressed while receiving endocrine therapy. Journal of Clinical Oncology 35 2875-2884. (https://doi.org/10.1200/JCO.2017.73.7585)

Spring LM, Zangardi ML, Moy B \& Bardia A 2017 Clinical management of potential toxicities and drug interactions related to cyclindependent kinase 4/6 inhibitors in breast cancer: practical considerations and recommendations. Oncologist 22 1039-1048. (https://doi.org/10.1634/theoncologist.2017-0142)

Stone A, Zotenko E, Locke WJ, Korbie D, Millar EK, Pidsley R, Stirzaker C, Graham P, Trau M, Musgrove EA, et al. 2015 DNA methylation of oestrogen-regulated enhancers defines endocrine sensitivity in breast cancer. Nat Commun 6 7758. (https://doi. org/10.1038/ncomms8758)

Sumi NJ, Kuenzi BM, Knezevic CE, Remsing Rix LL \& Rix U 2015 Chemoproteomics reveals novel protein and lipid kinase targets of clinical CDK4/6 inhibitors in lung cancer. ACS Chem Biol 10 2680-2686. (https://doi.org/10.1021/acschembio.5b00368)

Tadesse S, Yu M, Mekonnen LB, Lam F, Islam S, Tomusange K, Rahaman MH, Noll B, Basnet SK, Teo T, et al. 2017 Highly potent, selective, and orally bioavailable 4-thiazol-N-(pyridin-2-yl)pyrimidin2-amine cyclin-dependent kinases 4 and 6 inhibitors as anticancer drug candidates: design, synthesis, and evaluation. J Med Chem 60 1892-1915. (https://doi.org/10.1021/acs.jmedchem.6b01670)

Tadesse S, Bantie L, Tomusange K, Yu M, Islam S, Bykovska N, Noll B, Zhu G, Li P, Lam F, et al. 2018 Discovery and pharmacological characterization of a novel series of highly selective inhibitors of cyclin-dependent kinases 4 and 6 as anticancer agents. $\mathrm{Br} \mathrm{J}$ Pharmacol 175 2399-2413. (https://doi.org/10.1111/bph.13974)

Takahashi-Yanaga F \& Sasaguri T 2008 GSK-3beta regulates cyclin D1 expression: a new target for chemotherapy. Cell Signal 20 581-589. (https://doi.org/10.1016/j.cellsig.2007.10.018)

Taylor-Harding B, Aspuria PJ, Agadjanian H, Cheon DJ, Mizuno T, Greenberg D, Allen JR, Spurka L, Funari V, Spiteri E, et al. 2015 Cyclin E1 and RTK/RAS signaling drive CDK inhibitor resistance via 
activation of E2F and ETS. Oncotarget 6 696-714. (https://doi. org/10.18632/oncotarget.2673)

Teh JLF, Cheng PF, Purwin TJ, Nikbakht N, Patel P, Chervoneva I, Ertel A, Fortina PM, Kleiber I, HooKim K, et al. 2018 In vivo E2F reporting reveals efficacious schedules of MEK1/2-CDK4/6 targeting and mTOR-S6 resistance mechanisms. Cancer Discovery 8 568-581. (https://doi.org/10.1158/2159-8290.CD-17-0699)

Thangavel C, Dean JL, Ertel A, Knudsen KE, Aldaz CM, Witkiewicz AK, Clarke R \& Knudsen ES 2011 Therapeutically activating RB: reestablishing cell cycle control in endocrine therapy-resistant breast cancer. Endocr Relat Cancer 18 333-345. (https://doi.org/10.1530/ ERC-10-0262)

Tripathy D, Bardia A \& Sellers WR 2017 Ribociclib (LEE011): mechanism of action and clinical impact of this selective cyclin-dependent kinase 4/6 inhibitor in various solid tumors. Clinical Cancer Research 23 3251-3262. (https://doi.org/10.1158/1078-0432.CCR-16-3157)

Tripathy D, Im SA, Colleoni M, Franke F, Bardia A, Harbeck N, Hurvitz SA, Chow L, Sohn J, Lee KS, et al. 2018 Ribociclib plus endocrine therapy for premenopausal women with hormonereceptor-positive, advanced breast cancer (MONALEESA-7): a randomised phase 3 trial. Lancet Oncology 19 904-915. (http://doi. org/10.1016/S1470-2045(18)30292-4)

Valenzuela CA, Vargas L, Martinez V, Bravo S \& Brown NE 2017 Palbociclib-induced autophagy and senescence in gastric cancer cells. Exp Cell Res 360 390-396. (https://doi.org/10.1016/j. yexcr.2017.09.031)

Vijayaraghavan S, Karakas C, Doostan I, Chen X, Bui T, Yi M, Raghavendra AS, Zhao Y, Bashour SI, Ibrahim NK, et al. 2017 CDK4/6 and autophagy inhibitors synergistically induce senescence in $\mathrm{Rb}$ positive cytoplasmic cyclin E negative cancers. Nat Commun $\mathbf{8}$ 15916. (https://doi.org/10.1038/ncomms15916)

Vora SR, Juric D, Kim N, Mino-Kenudson M, Huynh T, Costa C, Lockerman EL, Pollack SF, Liu M, Li X, et al. 2014 CDK 4/6 inhibitors sensitize PIK3CA mutant breast cancer to PI3K inhibitors. Cancer Cell 26 136-149. (https://doi.org/10.1016/j.ccr.2014.05.020)
Wang L, Wang J, Blaser BW, Duchemin AM, Kusewitt DF, Liu T, Caligiuri MA \& Briesewitz R 2007 Pharmacologic inhibition of CDK4/6: mechanistic evidence for selective activity or acquired resistance in acute myeloid leukemia. Blood 110 2075-2083. (https:// doi.org/10.1182/blood-2007-02-071266)

Witkiewicz AK, Knudsen KE, Dicker AP \& Knudsen ES 2011 The meaning of p16(ink4a) expression in tumors: functional significance, clinical associations and future developments. Cell Cycle $\mathbf{1 0}$ 2497-2503. (https://doi.org/10.4161/cc.10.15.16776)

Witkiewicz AK, Ertel A, McFalls J, Valsecchi ME, Schwartz G \& Knudsen ES 2012 RB-pathway disruption is associated with improved response to neoadjuvant chemotherapy in breast cancer. Clinical Cancer Research 18 5110-5122. (https://doi.org/10.1158/1078-0432. CCR-12-0903)

Xu B, Krie A, De P, Williams C, Elsey R, Klein J \& Leyland-Jones B 2017 Utilizing tumor and plasma liquid biopsy in treatment decision making for an estrogen receptor-positive advanced breast cancer patient. Cureus 9 e1408. (https://doi.org/10.7759/cureus.1408)

Yang C, Li Z, Bhatt T, Dickler M, Giri D, Scaltriti M, Baselga J, Rosen N \& Chandarlapaty S 2017 Acquired CDK6 amplification promotes breast cancer resistance to CDK4/6 inhibitors and loss of ER signaling and dependence. Oncogene 36 2255-2264. (https://doi. org/10.1038/onc.2016.379)

Yin L, Li H, Liu W, Yao Z, Cheng Z, Zhang H \& Zou H 2018 A highly potent CDK4/6 inhibitor was rationally designed to overcome blood brain barrier in gliobastoma therapy. European Journal of Medicinal Chemistry 144 1-28. (https://doi.org/10.1016/j. ejmech.2017.12.003)

Yoshida A, Lee EK \& Diehl JA 2016 Induction of therapeutic senescence in vemurafenib-resistant melanoma by extended inhibition of CDK4/6. Cancer Research 76 2990-3002. (https://doi. org/10.1158/0008-5472.CAN-15-2931)

Zagorski WA, Knudsen ES \& Reed MF 2007 Retinoblastoma deficiency increases chemosensitivity in lung cancer. Cancer Research $\mathbf{6 7}$ 8264-8273. (https://doi.org/10.1158/0008-5472.CAN-06-4753)

Received in final form 5 September 2018

Accepted 17 September 2018

Accepted Preprint published online 18 September 2018 (c) 2019 Society for Endocrinology Published by Bioscientifica Ltd. Printed in Great Britain 